\title{
The Mechanics of a Saturated Silty Loess and Implications for Landslides
}

Ling $\mathrm{Xu}^{\mathrm{a}^{*}}$, Matthew Richard Coop ${ }^{\mathrm{b}}$, Maosheng Zhang ${ }^{\mathrm{c}}$, Genlong Wang ${ }^{\mathrm{c}}$

a. Xi'an Jiaotong University, Xi'an, China; formerly Institute of Geology and Geophysics, Chinese Academy of Sciences, Beijing, 1000029, China.

b. University College London; formerly City University of Hong Kong, Hong Kong, China.

c. Key Laboratory for Geo-hazard in Loess Area, Ministry of Land and Resources, Xi'an Center of China Geological Survey, Xi'an 710054, China.

*Corresponding: suyu820@163.com (Ling Xu) 


\section{Highlights}

1. The mechanics of a saturated silty loess were examined by means of triaxial and oedometer tests.

2. Comparisons between intact and reconstituted samples demonstrated a strong effect of structure.

3. The effects of structure are similar to those in clayey loess though they have different properties. 


\section{Abstract}

The results from an intensive experimental investigation on a loess that was retrieved from a typical silty loess zone in the north-western Chinese Loess Plateau are presented and interpreted. Triaxial and oedometer tests were performed on intact and reconstituted samples in a saturated condition. The soil behavior was found to be strongly affected by structure. The compression paths of the intact samples crossed the intrinsic compression line of the reconstituted soil and reached well-defined gross yield points, after which the compression paths converged towards the intrinsic compression lines. Two critical state lines were defined for the intact and reconstituted soils in the volumetric plane as a result of a robust element of natural structure. Comparisons were made with a structured clayey loess retrieved from the south-eastern Loess Plateau. It was found that the effects of structure on the behavior of the two loess soils are similar though they are very different in natural properties. This indicates that their natural structures might have experienced similar forming processes, perhaps related to their common origin. Catastrophic flowslides commonly occur in the study area, and the patterns of behavior observed in the laboratory tests may create some new insights into mechanisms of landslide initiation and subsequent movement as discussed in the study.

Keywords: Loess; Structure/Fabric; Laboratory Tests; Landslides 


\section{Introduction}

Earth slopes and high vertical cliffs in loess are frequently observed to be stable for long periods in NW China. Under low moisture contents, the structure and suction provide loess with sufficient shear strength to resist slope failure (Gao, 1988; Lin \& Wang, 1988), but these slopes may suddenly collapse once wetted or saturated (Delage et al., 2005; Derbyshire et al., 2001; Dijkstra et al., 2001). The behavior of loess has been extensively investigated (Derbyshire, et al., 1994; Wen \& Yan, 2013; Rogers et al., 1994; Muñoz-Castelblanco et al., 2011; Jiang et al., 2012; Jiang et al., 2014. The effects of natural structure are likely to play an important role in the landslide processes and $\mathrm{Xu}$ and Coop (2016) investigated the influence of structure on the behavior of a saturated clayey loess. However, the loess soils from different areas are usually different in physical-chemical composition and in the micro-characteristics of structure (Liu, 1985; Lin \& Wang, 1988; Wen \& Yan, 2013). However, these studies have generally not highlighted the roles of structure in the mechanics of the soils through detailed comparison of intact and reconstituted behavior and how that changes with location. A comparison of the influences of structure on behavior between different types of loess is therefore necessary.

There is also an urgent need for a combined study of the behavior of intact and disturbed loess for engineering practice. For example, the tops of silty loess-covered hills in the Lanzhou area are being removed to fill in valleys to create flatter land on which to build (Li et al., 2014). The mechanics of the intact and disturbed silty loess are extremely 
important for these projects. In research on flowslides the effects of structure on soil behavior in landslides needs to be identified and clarified. For example, is the critical state line location and shape in the volumetric plane the same for the intact and remolded silty loess? This is an important question because liquefaction has been usually taken as a critical mechanism for catastrophic flowslides in loess (Zhang et al., 2009; Xu et al., 2011; Xu et al., 2012; Zhang et al., 2013), and for other soils liquefaction can be related to the state in the volumetric plane relative to the critical state line (e.g. Carrera et al., 2011). Many laboratory testing programs in landslide studies were designed to test solely intact loess samples (Zhang et al., 2009; Xu et al., 2011; Xu et al., 2012; Zhou et al., 2014; Wang et al., 2015). Hence, the differences and links between the behavior of intact and remolded loess are still unclear.

The intent of the research presented here is to explore the mechanics of a silty loess in the Lanzhou area, NW China. The samples were retrieved from a loess platform where flowslides widely occur. A series of triaxial and oedometer tests on intact and reconstituted samples were performed. All tests were performed on saturated loess, after taking into account that these landslides commonly initiate in saturated layers. The test results were first interpreted in the context of the macro-mechanical behavior of the soil and then a systematic comparison with the clayey loess from the south-eastern Chinese Loess Plateau, tested by Xu \& Coop (2016) has been made. While Xu and Coop examined the influence of different depths at one location for the clayey loess, this paper therefore focusses on the differences in the behavior of the loess with two 
different gradings at different locations. Comparing only two soils, the study of the influence of grading is of course not exhaustive, but is sufficient to highlight its main effects along with similarities of the effects of structure for each soil. The liquefaction potential of the silty loess and its implications for flowslides are also discussed.

\section{Study area, materials and procedures}

The samples used in this study were retrieved from the undisturbed backscarp of a flowslide in Heifangtai, about 42 km west of Lanzhou city, Gansu Province (Fig. 2). Long-term irrigation on the ground surface for farming has significantly raised the groundwater table (Xu et al., 2014). Dozens of loess flowslides have occurred in the eastern and northern margins (Fig. 2). Efforts were made to take the deeper soils where liquefaction might most probably occur. The bottom loess soils of the platform have been saturated due to irrigation (Fig. 2a), which would complicate retrieval and so partially saturated intact samples from about $30 \mathrm{~m}$ depth were taken for the study. A block sampling method was adopted clearing at least $1 \mathrm{~m}$ of superficial loess prior to excavation. The blocks were carefully trimmed by hand and sealed using layers of cling-film (plastic wrap) and wax.

The in-situ dry density of the silty loess is $1.46-1.48 \mathrm{~g} / \mathrm{cm}^{3}$ with a void ratio of 0.83 0.85. Figure 3 shows the particle size distributions of the silty loess tested. The amount of silt $(0.002-0.075 \mu \mathrm{m})$ in the soil is up to about $90 \%$ and the clay fraction $(<0.002 \mu \mathrm{m})$ is up to $10 \%$. A comparison with the "clayey loess" tested by Xu \& Coop (2016) reveals 
that the clay content in the silty soil is less than clayey loess that has up to about $20 \%$. Mineralogical analysis showed that the predominant mineral is quartz, with smaller amounts of albite and calcite and significant quantities of clay minerals. Compared with samples of the clayey loess from two depths in Jingyang, Shannxi Province, the contents for this silty loess of quartz, albite, potassium feldspar, and dolomite are a little greater but slightly smaller for montmorillonite, illite and calcite (Table 1). Overall the clay mineral contents are larger than are apparent in the particle size distributions and the differences between the two soils are less than might be expected from their traditional names.

Figure 4 shows typical micro-structures of the intact specimens from SEM observations on broken horizontal and vertical surfaces. It appears that the silty particles in the loess have a platy shape and these are more visible as flat surfaces in the horizontal plane than the vertical. The finer particles in the soil tend to be clustered into aggregates with different sizes as shown in the higher magnification images of Fig.4c. Larger voids occur between the skeleton silty particles and aggregates, while smaller internal pores can be seen in some aggregates. Cement bonding between particles was local in nature and not pervasive throughout the samples. The bonding was composed of salts, as has been widely reported in China (e. g. Zhang et al., 2013). These salts are washed out from the loess platform and can be observed as white materials in Figs.2a, b and c.

The dimensions of the triaxial samples were $38 \mathrm{~mm}$ diameter and $76 \mathrm{~mm}$ length. The oedometer samples were $50 \mathrm{~mm}$ diameter and $20 \mathrm{~mm}$ height. The reconstituted samples 
for both triaxial and oedometer tests were made from the trimmings of the intact samples and were created by the moist tamping method. The well graded nature of the samples precluded the use of many sample preparation methods because of problems of segregation. Efforts were made in the reconstituted sample preparation to avoid any macro-voids remaining, while using the undercompaction method of Ladd (1978).

The triaxial samples were flushed first and then were saturated under back pressure until B values of at least 95\% were achieved. For some loose reconstituted specimens, the initial volume adopted was measured by dismantling the triaxial cell chamber after saturation, using an equivalent negative pore pressure to fix the specimen while new dimensions were taken. This also highlighted the volume change arising from any collapse on saturation. In the consolidation stage, the triaxial samples were all isotropically compressed in small steps to a variety of stress levels. Once the consolidation was finished, they were then sheared in compression either undrained or drained. The undrained tests aimed at understanding how the undrained behavior changed with stress level and specific volume, particularly with regard to static liquefaction. Since the undrained tests generally gave compressive behavior, drained tests were also performed to extend the stress range at critical state. No attempt was made to make direct comparisons between intact and reconstituted behavior at the same stress level and specific volume, since achieving exactly the same initial conditions is impossible in many cases because the intact soil can exist at states not achievable for the reconstituted. Instead, a more fundamental approach was adopted of conducting 
numerous tests over an extended stress range and making these comparisons through proper normalization for volume.

Tables 2 and 3 give details of all the tests. The accuracy of the initial specific volumes, $\mathrm{v}(=1+\mathrm{e})$ was ensured by using two methods of calculation, the first method measuring the initial dimensions and weights of the samples and the second the water contents at the ends of the tests together with the volumetric strains measured during testing. An average value of $\mathrm{v}$ is reported in Tables 1 and 2. Most of the tests are within an accuracy of less than \pm 0.01 , when comparing the methods. Any tests for which the differences between the two values were more than 0.04 were discarded, corresponding to an accuracy of \pm 0.02 .

\section{Results and interpretation}

\subsection{Compression Behavior}

Figure 5 presents the one-dimensional and isotropic compression results for intact and reconstituted loess samples. It was found that the compression curves for reconstituted samples of this loess had still not quite converged at the ends of the tests at vertical stresses of up to $7 \mathrm{MPa}$ (Fig.5a). This indicates that the silty loess has a slight tendency to transitional behavior at these stress levels (Altuhafi et al., 2010; Shipton \& Coop, 2012). Nevertheless, a one-dimensional ICL has been identified from the looser samples. The ICL of a clayey loess was also illustrated in this figure. The silty loess is higher and somewhat flatter than that for the more plastic clayey loess, as expected. Figure $5 \mathrm{~b}$ 
shows the isotropic compression data, which are for lower stress levels and so for the reconstituted samples the compression curves are strongly dependent on the initial density as they have not been loaded far enough to reach the isotropic ICL, which is consistent with the oedometer results. The oedometer test data of intact loess samples have been plotted on Fig.5b using a $\mathrm{K}_{0}$ value estimated from 1 -sin $\phi^{\prime}$. An estimated isotropic ICL is shown on Fig.5b that is parallel to the 1D ICL on Fig.5a.

The intact samples have very high initial specific volumes and as shown in Figs.5a and b, the intact compression paths clearly reach states outside the ICLs. The gross yield points can be identified as the points where the stress-volume behavior changes significantly, after which the paths tend to converge with the ICLs. The term "gross yield" is adopted as used in the sensitivity framework of Cotecchia \& Chandler (2000). Prior to yield, the intact loess is relatively incompressible compared to the reconstituted soil, while after yield it becomes more compressible. It is interesting that the isotropic and one-dimensional data are practically coincident for the intact soil, and this does indicate the good consistency between the oedometer and triaxial tests. The compression data highlight that even for a saturated silty loess the effects of structure can be very significant, as observed in SEM images in Fig.4.

Burland (1990) proposed normalizing the compression data of intact clay samples relative to the gradient and intercept of the reconstituted soil in order to highlight the effects of structure, defining the void index, $\mathrm{I}_{\mathrm{v}}$ : 
$I_{v}=\frac{e-e_{100}^{*}}{e_{100}^{*}-e_{1000}^{*}}$

where $e^{*}{ }_{100}$ and $e^{*} 1000$ are the void ratios on the $1 \mathrm{D}$ ICL at 100 and $1000 \mathrm{kPa}$. Xu \& Coop (2016) adopted this technique also for the clayey loess and Fig.6a shows the normalized data for the silty loess, where it again works well, although the curvature of the 1D ICL from Fig.5a is slightly smaller for both loess soils than for the sedimentary clays analyzed by Burland. The data for the intact samples resemble those of Feda et al. (1993) for a European loess. It is remarkable that the effects of structure in the silty and clayey loess that are taken from sites around 500km apart are similar, with gross yield states similar distances outside the 1D ICL being reached and similar rates of destructuration after yield. This is perhaps an indication that the structures of the two soils are similar as a result of their common origin and similar geological histories, the key difference between them being simply the grading which, for a wind deposited material, varies with distance from the source area. The SEM images for the clayey loess had also revealed a qualitatively similar structure with aggregates of platy shaped particles and localized bonding.

As shown in Fig.6a the gross yield points for the intact loess soils are quite close to the estimated past maximum total stresses. The sampling depth was above the natural perched water table (Xu et al., 2014), but the effects of past in-situ suction cannot be significant in the soil or the yield stresses would have been increased above the applied total stress under the influence of that suction. The gross yield points and possible in- 
situ maximum stresses both plot close to the Sedimentation Compression Line (SCL) defined for the in-situ states of normally consolidated clays (Burland, 1990). This is an indication that the soils should only have a sedimentation structure, as suggested by Cotecchia \& Chandler (2000), so that the formation of the structure would have been coincident with rather than subsequent to burial. If the soils had had a postsedimentation structure created after burial, then the gross yield points would plot outside the SCL. The silty loess sample yields a little further from the line than the clayey loess soils, but this could be simply due to some natural variability in the two soils.

Taking into account that Burland's void index is only defined in terms of vertical stress for one-dimensional compression, a new parameter $v_{n}$, was defined by Coop \& Cotecchia (1995) in terms of invariants:

$v_{n}=\exp \left(\frac{\left.\ln (v)-N^{*}\right)}{\lambda^{*}}\right)$

where the normal compression line of the reconstituted soil is defined, as suggested by Butterfield (1979):

$\ln v=N^{*}-\lambda^{*} \ln p^{\prime}$

Figure $6 \mathrm{~b}$ shows the normalized volumetric compression data using $v_{n}$, for the intact and reconstituted loess samples. Although the equations are defined in natural logs, 
$\log _{10}$ scales are shown for convenience. This method of normalization uses the isotropic normal compression line of the reconstituted soil rather than the one-dimensional as the reference condition and so the isotropic ICL plots on the figure as straight with a gradient of -1 . The isotropic ICL could not be identified clearly for this silty loess, without high pressure testing, so its location has been assumed to be parallel with the 1D ICL and lying slightly above it, using the same small spacing between the two ICLs as was identified for the clayey loess by Xu \& Coop (2016). As shown in Fig.5b the chosen isotropic ICL seems to coincide with the isotropic compression paths very well. The isotropic and 1D data for the intact samples are shown for the silty loess and also for the two depths of clayey loess for comparison. Again, the data show very consistent effects of structure despite the very different natures of the soils.

\subsection{Shearing Behavior}

\section{Stress-strain response}

Figure 7 presents typical results of the undrained tests on intact and reconstituted samples. As highlighted above, direct comparisons between intact and reconstituted samples at the same stress and volume states are difficult because the intact soil can exist at states that are impossible for the reconstituted. Nevertheless, some general comparisons can be made. To reach critical states, most of the tests were stopped at axial strains of at least $30 \%$ at which point they had generally reached constant stress and volume states, although there are some small continued changes for some samples. The initial states of most of the triaxial tests on reconstituted samples are below the 
oedometer ICL, because it was very difficult to construct triaxial samples of higher initial specific volumes. Three tests at higher confining stresses of more than $500 \mathrm{kPa}$ are on or near the isotropic ICL (Fig.5b). The initial states prior to shearing for the intact samples are all above the isotropic ICL.

The deviator stresses and the changes of pore pressures are both normalized by the initial effective confining pressure, $p_{0}^{\prime}$. It can be seen that intact loess reaches peak strengths at axial strains less than $2 \%$ with a sharp initial increase in pore water pressure, followed a marked strain softening, which might be defined as flow liquefaction behavior, although true liquefaction, which some authors define as reaching zero $p^{\prime}$ (e.g. Carrera et al., 2011) does not occur. Nevertheless, very low p' values are reached and to ensure the accuracy of the data, they have been corrected for membrane restraint using the method suggested by Bishop \& Henkel (1957) and La Rochelle et al. (1988) which was applied to the measured deviatoric stress for a barrelling type of deformation. The response of the intact loess to monotonic loading is highly dependent on the confining pressure. The normalized deviator stress at peak decreases rapidly with increasing confining pressure, while the normalized pore pressure increases. The isotopic confining pressure at yielding is about 200kPa for the intact loess (Fig.5b), so that tests UU_02_300kPa and UU_04_400kPa reach their peaks more quickly and strain soften less dramatically than UU_03_50kPa and UU_01_100kPa. The behavior of the reconstituted samples is simply related to their initial density, the denser ones being dilative and the looser contractive, but they are all much less brittle than the intact 
samples.

The differences between the intact and reconstituted samples can be also found in the shearing stress paths (Fig.8). The loose reconstituted samples at higher stresses RU_04_600kPa and RU_05_550kPa, have a strongly contractive behavior, like the intact, but with a less dramatic strain softening, before developing dilative "tails" to the stress paths at large strains. They show a typical temporary instability behavior as found in silty sands (e.g. Yamamuro \& Lade, 1998), with "quasi-steady states" or phasetransformation points. However, the stress paths do not show the same tendency for flow liquefaction as the intact samples, that reach very low values of $p^{\prime}$ at the ends of the tests. For the denser reconstituted samples, the mode of behavior becomes a completely dilative and stable one, for example test RU_02_620kPa which has an initial specific volume of 1.60. The reconstituted loess has a quite conventional behavior in undrained shearing similar to many other soils, such as loose crushable soils (e.g. Hyodo et al., 1998), silts (e.g. Boulanger \& Idriss, 2006) or sands (e.g. Vaid \& Sivathayalan, 2000).

Figure 9 presents typical results of drained tests on reconstituted and intact samples. The intact loess shows a greater contractive behavior than the reconstituted. This is consistent with Figs.7 and 8, again indicating the effects of natural structure as observed in Fig.4. The intact and reconstituted samples are generally strain hardening up to the critical state, except for one denser reconstituted sample (RD_02_200kPa), which has 
a gentle peak corresponding to a slightly dilative behavior at large strains. The behavior of the intact soil is distinctly stiffer initially than the reconstituted, again with clear gross yield points similar to those seen in compression at which points the stress-strain behavior softens significantly. At larger strains, the normalized deviator stresses for the reconstituted samples are higher than for the intact samples though the intact loess continues to strain harden after gross yield, reaching similar values at the ends of the tests. The effects of structure are also highlighted in Fig.9c in terms of the stress ratio, $q / p^{\prime}$ plotted against the volumetric strain.

In Fig.10 the stress-strain data of all the tests on intact and reconstituted samples are represented by the stress ratio, $q / p^{\prime}$, but using he current value of $p^{\prime}$ rather than the initial value $p_{0}^{\prime}$. Again, the intact samples can be seen to be stiffer for similar loading conditions, despite generally having higher initial specific volumes, but they all tend towards a final ratio $M$ of 1.38 , most tests being within about \pm 0.05 of this value, which corresponds to a critical state angle of shearing resistance, $\phi_{\mathrm{cs}}^{\prime}$ of $34.1^{\circ}$. This is slightly higher than the clayey loess from $20 \mathrm{~m}$ depth, which gave $\mathrm{M}$ and $\phi_{\mathrm{cs}}^{\prime}$ of 1.35 and $33.4^{\circ}$ (Xu \& Coop, 2016), as expected for the coarser grading, and significantly higher than the $50 \mathrm{~m}$ clayey loess that gave 1.25 and $31.1^{\circ}$.

\section{Stress-dilatancy behavior}

The stress-dilatancy relationships for the drained tests on the reconstituted and intact loess are given in Figs.11a and b, respectively. In the absence of elastic shear and bulk 
moduli, the total volumetric strains and shear strains, calculated as $\varepsilon_{\mathrm{S}}=\varepsilon_{\mathrm{v}}-\varepsilon_{\mathrm{a}} / 3$, were adopted for the calculation of the soil stress-dilatancy relationships. The gradients have been taken by regression over short sections of the $\varepsilon_{\mathrm{s}}: \varepsilon_{\mathrm{v}}$ graph. Some scatter in the data at low stress ratios is mainly because the rate of dilation is calculated as the ratio of two small increments of strain.

The data for the intact samples have been compared with the reconstituted samples. This reveals a significant influence of the natural structure. At small strains the paths of intact loess initially reach higher stress ratios than the equivalent reconstituted soil, but then tend towards the same critical state $\mathrm{M}$ at large strains. Tests on overconsolidated samples and a dense sample for the reconstituted loess were also performed. These define the same relationship at larger strains, but with much greater dilation and higher peak states, especially for the dense sample. The relationships for the clayey loess, also illustrated in the Fig. 11 are very close to that of the silty loess, but with different $\mathrm{M}$ values.

\section{Critical states}

Figure 12(a) shows the critical states in deviator stress against effective mean stress space for all the tests, drained and undrained, on intact and reconstituted samples. Note that the end of test states have been assumed to be critical states. These again confirm the same value of $M=1.38$ at critical state. Figure 12(b) shows the shearing paths in $v$ -

$p^{\prime}$ space. For consistency with the $v_{n}$ graph the shearing paths are shown using $\ln v$ and 
$\ln p^{\prime}$ axes. The paths followed by the intact samples are more strongly compressive than reconstituted samples, with greater volume changes for the drained tests and larger pore pressure increases for the undrained at the same stress levels, and this can be seen to result from the effects of structure causing the intact samples to start from states much further to the right and above the critical state line than the reconstituted. It is also clear that the intact samples have a critical state line that lies higher than that of the reconstituted samples even though they exhibit this strongly compressive behavior.

Two horizontal samples (UU06 $†$ _300kPa and UD08† $510 \mathrm{kPa}$ ) for intact loess and also several overconsolidated samples for intact and reconstituted loess were tested in this study. As shown in Fig.12, neither the sample orientation nor overconsolidation were found to cause any significant influence on the critical states. Only one very dense sample sheared at $50 \mathrm{kPa}$ fails to reach a state close to the defined critical state line and this may be due to strain localization. It is probable that two dense reconstituted samples with end of test states at around 1000kPa have not quite reached critical states, as they plot below the straight chosen line, and it is unlikely that the line would become steeper as $p^{\prime}$ increases.

It is interesting to note that the CSLs in $\ln v$ - $\ln p^{\prime}$ space seem to start to curve towards horizontal asymptotes at low stress levels as are expected from coarser grained soils (e.g. Verdugu \& Ishihara, 1996), whether or not a logarithmic v axis is used. Curved CSLs for loess have not generally been reported in literature, for which straight CSLs 
are usually adopted (e.g. Xu et al., 2011; Zhou et al., 2014; Wang et al., 2014). The spacing between the two CSLs in terms of specific volume is around 0.045, which represents a volumetric strain of about $2.5 \%$ for the initial specific volumes of the samples. The CSLs for the clayey loess (Xu \& Coop, 2016) are also illustrated in this figure; both depths gave similar lines in the volumetric plane. For more plastic soils CSLs are typically straighter to lower stress levels, but the lack of test data at lower confining stresses for the clayey loess means that this cannot be confirmed, but at stresses over about $30 \mathrm{kPa}$ both were straight. Although the gradients are very different, the spacings between the pairs of CSLs are more similar.

The normalized specific volume $v_{n}$ proposed by Coop \& Cotecchia (1995) can also highlight the effects of structure for a soil in shearing, which the $I_{v}$ plot cannot. Figure 13 presents CSLs for both reconstituted and intact samples $\left(\mathrm{CSL}_{\mathrm{r}}\right.$ and $\left.\mathrm{CSL}_{\mathrm{i}}\right)$ for both the silty loess and clayey loess in the $\ln v_{n}: \ln p^{\prime}$ plane and in the normalized plane they are parallel to the ICL until the curvature of the CSLs starts at lower stress levels. The $\mathrm{CSL}_{\mathrm{i}}$ at high stress levels for both soils plot approximately on the isotropic ICL, but this is merely coincidence. Their $\mathrm{CSL}_{\mathrm{r}}$ are also at similar distances below the isotropic ICLs. It is therefore surprising that despite the large differences in the locations (Fig. 1), gradings and gradients of the CSLs for the loess soils at different sites on the Chinese Loess Plateau, when normalized the behavior is remarkably similar, but this is consistent with the similarity also for the normalized compression behavior (Fig. 6). These similarities indicate that the soils have a similar predominantly similar 
sedimentation structures, as defined by Cotecchia \& Chandler (2000), so that the formation of the structure should have been coincident with rather than subsequent to burial, and since they are likely to have experienced similar geological histories the magnitude of the effects of structure is similar.

The two different CSLs for the intact and reconstituted samples indicates that the strains needed to reach a constant fabric could be very large indeed (e.g. Nougier-Lehon et al., 2005). This has been seen for other soils so that the CSL of the intact soil as defined in triaxial testing need not correspond with that of the reconstituted (Cotecchia \& Chandler, 2000; Baudet \& Stallebrass, 2004). Figure 14 shows SEM images of the intact and reconstituted soils after triaxial shearing (UD_05_150kPa and RD_07_150kPa). The intact sample (Figs.14a \& b) has a denser fabric than before shearing (Fig.4) as a result of the strong volumetric compression it has experienced. There is still the evident preferential orientation of the particles in the horizontal plane and areas of the amorphous coating, possibly cementing, could still be found. The intact soil still has some larger pores between skeleton particles and aggregates could be still observed. In contrast, in the reconstituted soil it is not easy to find large pores. The particles are stacked in a disorderly manner, indicating a denser fabric (Figs.14c \& d). Figures 14e and $f$ are higher magnification images showing in greater detail the fabric for sheared intact and reconstituted samples. The reconstituted and intact samples were both sheared drained at $150 \mathrm{kPa}$ and the denser fabric of the reconstituted soil explains the lower specific volumes at critical state (Fig.12b) and so the lower location of the CSL 
of the reconstituted soil than the intact in the volumetric plane. It would be unlikely that further monotonic shearing at this magnitude of strains would change this.

\section{Normalized boundary surfaces}

The stress paths of the intact and reconstituted loess samples have been normalized for volume by an equivalent pressure taken on the CSL, $p^{\prime}{ }_{\mathrm{cs}}$, defined as:

$p_{\mathrm{CS}}^{\prime}=\exp \left(\frac{\Gamma^{*}-\ln V}{\lambda^{*}}\right)$

where $\lambda^{*}$ and $\Gamma^{*}$ are the gradient of the CSL and its intercept at intercept at $1 \mathrm{kPa}$ in the $\ln v: \ln p^{\prime}$ plane. Hence, the straight segments of the CSLs as shown in Fig.12b were used here to calculate the equivalent pressure, neglecting the curvature at low stress levels. Because of the slightly different $M$ values for the two soils, the values of $\mathrm{q} / \mathrm{p}^{\prime} \mathrm{cs}$ have been further divided by $\mathrm{M}$ for ease of comparison.

Figure 15a shows a clear reconstituted or intrinsic state boundary surface $\left(\mathrm{SBS}_{\mathrm{r}}\right)$, defined by normalizing the paths of the reconstituted samples. When identifying the state boundary surfaces, to reduce the scatter of the normalized paths arising from small inaccuracies in specific volume, the final specific volumes for some tests have been slightly adjusted to lie on the chosen CSL. However, for test RU_06_16kPa the specific volume of the sample was not adjusted because it reaches its critical state on the curved part of the $\mathrm{CSL}_{\mathrm{r}}$ and so on this plot its normalized shearing path ends to the left of the reconstituted $\mathrm{CSL}_{\mathrm{r}}$. The shape of the intrinsic surface is more similar to those of sands 
(e.g. Coop \& Lee, 1993) than those of clays (e.g. Hosseini-Kamal et al., 2014), as the $\mathrm{CSL}_{r}$ lies to the left of the apex of the boundary surface, although the spacing ratio of about 2.3 is less than those typically found for sands.

Figure $15 \mathrm{~b}$ shows the intact state boundary surface $\left(\mathrm{SBS}_{\mathrm{i}}\right)$, defined by normalizing the stress paths of the tests on intact samples with respect to the $\mathrm{CSL}_{\mathrm{i}}$. The straight segment of the $\mathrm{CSL}_{\mathrm{i}}$ in the $\ln v: \ln p^{\prime}$ plane has again been used for the normalization. The $\mathrm{SBS}_{\mathrm{i}}$ is compared with the reconstituted $\mathrm{SBS}_{\mathrm{r}}$ normalized with respect to the $\mathrm{CSL}_{\mathrm{r}}$. The size of the $\mathrm{SBS}_{\mathrm{i}}$ is considerably larger than the $\mathrm{SBS}_{\mathrm{r}}$, resulting from the effects of structure. Once isotropic compression prior to shearing takes the initial state past the gross yield, the normalized stress paths tend to collapse back towards the $\mathrm{SBS}_{\mathrm{r}}$, behavior that is again similar to the clayey loess (Xu \& Coop, 2016), cemented sands (e.g. Cuccovillo \& Coop, 1999) or structured clays (Cotecchia \& Chandler, 2000). Figure 16c compares the two boundary surfaces when they are both normalized with respect to the intrinsic critical state line. The size of the $\mathrm{SBS}_{\mathrm{i}}$ for intact loess becomes much larger than the $\mathrm{SBS}_{\mathrm{r}}$ for the reconstituted samples, an effect of the separation of the two surfaces in volumetric space.

A considerable difference between the undrained and drained tests on intact samples can be found in the normalized space. Compared with undrained loading, the normalized drained tests for low to medium stress levels reach large stress ratios before a gross yield at which the stress path changes direction abruptly and drops rapidly back 
towards the critical state, while the undrained paths are more gently curved throughout. This is again similar to clayey loess (Xu \& Coop, 2016). The differences between horizontal and vertical intact samples are also clear in the normalized stress paths. At lower stress levels the path at $300 \mathrm{kPa}$ for the vertical sample reaches larger stress ratios more quickly than that on the horizontal. This is an indication of significantly anisotropic behavior in the intact loess. The separation of the normalized stress paths between the vertical and horizontal samples becomes smaller as the initial confining stress level increases and the anisotropic behavior observed at $510 \mathrm{kPa}$ is much weaker than at $300 \mathrm{kPa}$, perhaps because this is beyond the yielding point in compression (Fig.5).

The SBSs for the intact and reconstituted clayey loess are also illustrated in Fig.15 (Xu \& Coop, 2016) for comparison with the silty loess. The intrinsic behavior demonstrated by the normalized paths for the reconstituted samples (Fig.15a) is very similar, even though the ICLs and CSL ${ }_{r}$ are very different (Fig.5a and Fig.12b). For the intact samples, the $\mathrm{SBS}_{\mathrm{i}}$ normalized with respect to the $\mathrm{CSL}_{\mathrm{i}}$ for the two soils has similar shapes at larger strains once the shearing paths have passed the apex of the boundary surface. But prior to this the $\mathrm{SBS}_{\mathrm{i}}$ for the clayey loess has a highly anisotropic shape, and a much sharper reversal at the apex. In Fig.16c the sizes of the $\mathrm{SBS}_{\mathrm{i}}$ for the intact soils are also larger for the clayey loess than the silty, indicating a greater effect of structure, in contrast to what was seen in compression. 


\section{Discussion}

Critical state soil mechanics is commonly used as a framework for the interpretation of soil behavior. Conventionally the critical state line is unique for different soil states, intact or reconstituted and so the existence of two different lines raises new problems in the strength evaluation for the silty loess. For example, the soil states involved at particular engineering sites should be identified before using this method so that the correct line is used. For first time slope stability problems in the intact loess, the $\mathrm{CSL}_{\mathrm{i}}$ should be adopted, while the $\mathrm{CSL}_{\mathrm{r}}$ might be more appropriate for problems encountered in loess disturbed to the point of remolding by previous slope failure processes, and for engineering applications where the soil is remolded or reconstituted, such as filled slopes. An error in selecting the correct CSL would cause the soil strength to be underor overestimated significantly, for example in soil liquefaction potential.

Dozens of catastrophic flowslides have been triggered by the long-term agricultural irrigation in the study area (Fig. 2). Liquefaction has been taken as the initiating mechanism (Wang et al., 1992; Zhang et al., 2013; Zhou et al., 2014). While Xu et al. (2012) studied the role of static liquefaction in initiation, that of liquefaction during the movement has not so far been clarified. Since in v- $p^{\prime}$ space the critical state line for the intact loess is significantly higher than the intrinsic CSL, it is probable that even after an initial static liquefaction further remolding during the movement would cause a greater breakdown of the structure than is achievable in triaxial compression, causing the $\mathrm{CSL}_{\mathrm{i}}$ to migrate to the $\mathrm{CSL}_{\mathrm{r}}$, increasing further the pore pressures, giving additional 
liquefaction potential and softening instability. This could contribute to the overall landslide movement, characterized by high-speeds and long run-outs. Similar migrations of CSLs through vigorous remolding in landsliding have been seen in the structurally complex clays of Italy (e.g. Fearon \& Coop, 2000, 2002). To explore further the influences of effects of structure on liquefaction-induced landslide processes, numerical analysis would be invaluable. However, these would require a constitutive model that accounted for the curvature of the CSLs in the volumetric plane as well as the effects of structure, along with the migration of the CSL to lower volumes due to destructuration at extremely large strains, and no such model yet exists.

\section{Conclusions}

An experimental study has been conducted on intact and reconstituted silty loess by means of oedometer and triaxial tests. The behaviors in compression and shearing were affected significantly by natural structure even in a saturated state. The intact samples reached well-defined gross yield points outside the intrinsic compression line of the reconstituted soil and defined an intact boundary surface that was significantly larger than that of the reconstituted soil. The data indicate that the intact structure also affects the stress-strain and stress-dilatancy relationships and even results in two different critical state lines in the volumetric plane for the intact and reconstituted soil, both of which curve towards horizontal asymptotes at lower stresses, increasing the tendency to static liquefaction. The existence of two critical state lines indicates that some more stable elements of fabric in the intact loess could not be removed by the strain levels 
imposed by triaxial testing. The data for the silty loess have been compared with those previously published for a clayey loess (Xu \& Coop, 2016). It was found that the two loess soils have very similar effects of structure even though they are different in intrinsic behavior, as a result of their different gradings and mineraolgies, perhaps a result of a common origin of their structures. The mechanics of the soils allows some significant insight into the understanding of landslide phenomena occurring in the study area.

\section{Acknowledgements}

The work was supported by the Natural Science Foundation of China (Project No. 41472276 and 41530640) and the Hong Kong Scholars Programme.

\section{References}

Altuhafi F., Baudet B.A., Sammonds P., 2010. The mechanics of subglacial sediment: an example of new "transitional behaviour". Canadian Geotechnical Journal 47(7), 775790.

Baudet, B., Stallebrass, S., 2004. A constitutive model for structured clays. Géotechnique 54(4), 269-278.

Boulanger, R., Idriss, I., 2006. Liquefaction susceptibility criteria for silts and clays. Journal of Geotechnical and Geoenvironmental Engineering, ASCE 132(11), 14131426. 
Burland, J.B., 1990. On the compressibility and shear strength of natural soils. Géotechnique 40(3), 329-378.

Bishop, A.W., Henkel D.J., 1957. The measurement of soil properties in the triaxial tests. Edward Arnold LTD, London, 190 pp.

Carrera, A., Coop, M.R., Lancellotta, R., 2011. Influence of grading on the mechanical behaviour of Stava tailings. Géotechnique 61(11), 935-946.

Coop, M.R., Cotecchia, F., 1995. The compression of sediments at the archaeological site of Sibari. In: Proc. 11th ECSMFE, Copenhagen, 8, 19-26.

Coop, M.R., Lee, I.K., 1993. The behaviour of granular soils at elevated stresses. In "Predictive Soil Mechanics" Houlsby, G.T. \& Schofield, A.N. eds. (Thomas Telford, London) (Proc.C.P.Wroth Memorial Symposium, 1992), 186-198.

Cotecchia, F., Chandler, R.J., 2000. A general framework for the mechanical behaviour of clay. Géotechnique 50(4), 431-447.

Cuccovillo, T., Coop, M.R., 1999. On the mechanics of structured sands. Géotechnique 49(6), 741-760.

Delage, P., Cui, Y.J., Antoine, P., 2005. Geotechnical problems related with loess deposits in Northern France. Proc. Int. Conf. on Problematic Soils, Eastern Mediterranean University, Famagusta, N. Cyprus, 1-24.

Derbyshire, E., Dijkstra, T.A., Smalley, I.J., Li, Y.J., 1994. Failure mechanisms in loess and the effects of moisture content changes on remolded strength. Quaternary International 24, 5-15. 
Derbyshire, E., 2001. Geological hazards in loess terrain, with particular reference to the loess regions of China. Earth-Science Reviews 54(1-3), 231-260.

Dijkstra, T.A., 2001. Geotechnical thresholds in the Lanzhou loess of China. Quaternary International 76/77, 21-28.

Gao, G.R., 1988. Formation and development of the structure of collapsing loess in China. Engineering Geology 25, 235-245.

Fearon, R.E., Coop, M.R., 2000. Reconstitution: what makes an appropriate reference material? Géotechnique 50(4), 471-477.

Fearon, R.E., Coop, M.R., 2002. The effect of landsliding on the properties of a structurally complex clay. Quarterly Journal of Engineering Geology and Hydrogeology 35(1), 25-32.

Feda, J., Bohac, J., Herle, I., 1993. Compression of collapsed loess: Studies on bonded and unbonded soils. Engineering Geology 34, 95-103.

Hosseini-Kamal, R., Coop, M.R., Jardine, R.J., Brosse, A., 2014. The post-yield behaviour of four Eocene-to-Jurassic UK stiff clays. Géotechnique 64(8), 620-634.

Hyodo, M., Hyde, A.F.L., Aramaki, N., 1998. Liquefaction of crushable soils. Géotechnique 48 (4), 527-543.

Jiang, M., Hu, H., Liu, F., 2012. Summary of collapsible behaviour of artificially structured loess in oedometer and triaxial wetting tests. Canadian Geotechnical Journal 49, 1147-1157. 
Jiang, M.J., Zhang, F.G., Hu, H.J., Cui, Y.J., Peng, J.B., 2014. Structural characterization of natural loess and remolded loess under triaxial tests. Engineering Geology 181, 249-260.

Ladd, R. S., 1978. Preparing test specimens using under-compaction. Geotechnical Testing Journal 1(1), 16-23.

Lin, Z.G., Wang, S.J., 1988. Collapsibility and deformation characteristics of deepseated loess in China. Engineering Geology 25, 271-282.

Li, P., Qian, H., Wu, J., 2014. Accelerate research on land creation. Comment article in Nature 5, 29-31.

Liu, T.S. (Ed.), 1985. Loess and the Environment. Science Press, Beijing, 215 pp.

La Rochelle P., Leroueil S., Trak B., Blais-Leroux L., Tavenas F., 1988. Observational approach to membrane and area corrections in triaxial tests. In: Advanced triaxial testing of soil and rock, ASTM STP 977: 715-731.

Muñoz-Castelblanco, J., Delage, P., Pereira, J.M., Cui, Y.J. 2011. Some aspects of the compression and collapse behaviour of an unsaturated natural loess. Géotechnique Letters 1(2), 17-22.

Nougier-Lehon, C., Vincens, E., Cambou, B., 2005. Structural changes in granular materials: the case of irregular polygonal particles. International Journal of Solids and Structures 42 (24-25), 6356-6375.

Rogers, C.D.F., Dijkstra, T.A., Smalley, I.J., 1994. Hydroconsolidation and subsidence of loess: Studies from China, Russia, North America and Europe. Engineering Geology 37(2), 83-113. 
Shipton, B., Coop, M.R., 2012. On the compression behaviour of reconstituted soils. Soils and Foundations 52(4), 668-681.

Vaid, Y.P., Sivathayalan, S., 2000. Fundamental factors affecting liquefaction susceptibility of sands. Canadian Geotechnical Journal 37(3), 592-606.

Wang, J.D., 1992. A mechanism of high-speed loess landslides: liquefaction of saturation loess due to creep. Geological Review 38(6), 532-538.

Wen, B.P., Yan, Y.J., 2013. Influence of structure on shear characteristics of the unsaturated loess in Lanzhou, China. Engineering Geology 168, 46-58.

Wang, G.L., Li, T.L., Xing, X.L. Zou, Y., 2015. Research on loess flow-slides induced by rainfall in July 2013 in Yan'an, NW China. Environmental Earth Sciences 73(12), 7933-7944.

Wang, G., Zhang, D., Furuya, G., Yang, J., 2014. Pore-pressure generation and fluidization in a loess landslide triggered by the 1920 Haiyuan earthquake, China: A case study. Engineering Geology 174, 36-45.

Xu, L., Dai, F., Tham, L.G., Tu, X., Jin, Y., 2011. Landslides in the transitional slopes between a loess platform and river terrace, Northwest China. Environmental \& Engineering Geoscience 17(3), 267-279.

Xu, L., Dai, F.C., Gong, Q.M., Tham, L.G., Min, H., 2012. Irrigation-induced loess flow failure in Heifangtai platform, North-West China. Environmental Earth Sciences 66, 1707-1713.

Xu, L., Dai, F.C., Tu, X.B., Tham, L. G., Zhou, Y.F., Javed Iqbal., 2014. Landslides in a loess platform, North-West China. Landslides 11(6), 993-1005. 
Xu, L., Coop, M.R. (2016) The Influence of structure on the behavior of a saturated clayey loess. Canadian Geotechnical Journal. in press.

Yamamuro, J.A., Lade, P.V., 1998. Steady-state concepts and static liquefaction of silty sands. J Journal of Geotechnical and Geoenvironmental Engineering, ASCE 124(9), 868-87.

Zhang, D.X., Wang, G.H., Luo, C., Chen, J., Zhou, Y., 2009. A rapid loess flowslide triggered by irrigation in China. Landslides 6, 55-60.

Zhang, F., Wang, G., Kamai, T., Chen, W., Zhang, D., Yang, J., 2013. Undrained shear behavior of saturated loess at different concentrations of sodium chlorate solution. Engineering Geology 155, 69-79.

Zhou, Y.F., Tham, L.G., Yan, W.M., Dai, F.C., Xu, L., 2014. Laboratory study on soil behavior in loess slope subjected to infiltration. Engineering Geology 183, 31-38.

\section{List of table}

Table 1. X-ray diffraction analyses of the materials

Table 2. Details of the oedometer tests

Table 3. Details of the triaxial tests

\section{List of figure}

Fig.1. Sample location of Heifangtai on the Chinese Loess Plateau

Fig.2. Site description and landslides

Fig.3. Particle size distributions of the loess samples

Fig.4. SEM images of the intact micro-structure of the loess (a) horizontal plane; (b) 
vertical plane; (c) higher magnification image showing pores between aggregates

Fig.5. Compression curves of reconstituted and intact samples: (a) oedometer tests; (b) isotropic compression curves from triaxial tests

Fig. 6. Normalized compression data for natural and reconstituted loess (a) using void index, Iv; (b) normalized specific volume, vn

Fig.7. Typical results of undrained triaxial tests (a) normalized deviator stress-axial strain curves, (b) normalized pore pressure responses $\left(\mathrm{R}^{* * *}\right.$ reconstituted, $\mathrm{U}^{* * *}$ undisturbed, ${ }^{*} \mathrm{D} * *$ drained, $* \mathrm{U}^{* *}$ undrained)

Fig.8. Stress paths of undrained triaxial tests (a) entire range of stresses; (b) enlargement for stresses less than $400 \mathrm{kPa}$

Fig.9. Typical results of drained triaxial test (a) volume changes-axial strain curves; (b) deviator stress-axial strain curves; (c) stress ratio-volume strain curves

Fig.10. Development of stress ratio for reconstituted and undisturbed specimens

Fig.11. Stress-dilatancy data for the drained tests on (a) reconstituted specimens; (b) undisturbed specimens

Fig.12. Critical states line in (a) q-p' space (b) the volumetric plane Fig. 13. Critical states line in the normalized volumetric plane Fig.14. SEM images of samples after shearing (a) intact sample (No. UD_05) horizontal surface; (b) intact sample (No. UD_05) vertical surface; (c) reconstituted sample (No. RD_07) horizontal surface; (d) reconstituted sample (No. RD_07) vertical surface; (e) higher magnification image for intact sample (No. UD_05) horizontal surface; (f) higher magnification image for reconstituted sample (No. RD_07) horizontal surface 
Fig.15. Normalized stress-paths of intact and reconstituted loess (a) Stress-paths of reconstituted samples normalized by p'cs using the intrinsic CSL; (b) Stress-paths of intact samples normalized by p'cs using intact CSL; (c) Stress-paths of intact samples normalized by p'cs using intrinsic CSL 
Table 1

X-ray diffraction analyses of the materials

\begin{tabular}{|c|c|c|c|c|c|c|c|c|c|c|}
\hline \multirow[b]{2}{*}{ Sample } & \multirow{2}{*}{$\begin{array}{l}\text { Quartz } \\
(\%)\end{array}$} & \multirow{2}{*}{$\begin{array}{l}\text { Albite } \\
(\%)\end{array}$} & \multirow{2}{*}{$\begin{array}{l}\text { Potassium } \\
\text { feldspar } \\
(\%)\end{array}$} & \multirow{2}{*}{$\begin{array}{l}\text { Calcite } \\
(\%)\end{array}$} & \multirow{2}{*}{$\begin{array}{l}\text { Dolomi } \\
\text {-te } \\
(\%)\end{array}$} & \multirow{2}{*}{$\begin{array}{l}\text { Hornb } \\
\text {-lende } \\
(\%)\end{array}$} & \multicolumn{4}{|c|}{ Clay Minerials } \\
\hline & & & & & & & $\begin{array}{l}\text { Montmor } \\
\text { Illonite } \\
(\%)\end{array}$ & $\begin{array}{l}\text { Illite } \\
(\%)\end{array}$ & $\begin{array}{l}\text { Kaolin } \\
\text {-ite } \\
(\%) \\
\end{array}$ & $\begin{array}{l}\text { Chlorite } \\
(\%)\end{array}$ \\
\hline $\begin{array}{c}\text { Clayey } \\
\text { loess_20m }\end{array}$ & 35.1 & 14.9 & 0.9 & 16.5 & 2.3 & 1.1 & 4.4 & 15.5 & 3.2 & 6.1 \\
\hline $\begin{array}{c}\text { Silty } \\
\text { loess_tested }\end{array}$ & 37.3 & 14.5 & 3.5 & 14.9 & 4.9 & 0.7 & 3.3 & 13.4 & 2.7 & 4.8 \\
\hline
\end{tabular}


Table 2

Details of the oedometer tests

\begin{tabular}{llllll}
\hline $\begin{array}{l}\text { Test } \\
\text { number }\end{array}$ & Sample style & $\begin{array}{l}\text { Method of sample } \\
\text { preparation }\end{array}$ & $\begin{array}{l}\text { Water } \\
\text { content }\end{array}$ & $\begin{array}{l}\text { Initial } \\
\text { specific } \\
\text { volume } v_{0}\end{array}$ & $\begin{array}{l}\sigma_{\text {vmax }}^{\prime} \\
(\mathrm{MPa})\end{array}$ \\
\hline O1 & Undisturbed & - & - & 1.849 & 7.167 \\
O2 & Reconstituted & Slurry & - & 2.001 & 7.167 \\
O3 & Reconstituted & Wet compaction & $10 \%$ & 2.120 & 7.167 \\
O4 & Reconstituted & Wet compaction & $10 \%$ & 1.695 & 7.167 \\
O5 & Reconstituted & Wet compaction & $10 \%$ & 1.558 & 7.167 \\
O6 & Reconstituted & Wet compaction & $10 \%$ & 1.537 & 7.167 \\
O7 & Reconstituted & Wet compaction & $10 \%$ & 1.503 & 7.167 \\
\hline
\end{tabular}


Table 3

Details of the triaxial tests

\begin{tabular}{|c|c|c|c|c|c|c|}
\hline \multirow[b]{2}{*}{$\begin{array}{l}\text { Test } \\
\text { name }\end{array}$} & \multirow[b]{2}{*}{$\begin{array}{l}\text { Specific } \\
\text { volume } \\
\text { after } \\
\text { saturation }\end{array}$} & \multirow[b]{2}{*}{$\begin{array}{l}\text { Confining } \\
\text { effective } \\
\text { stress } \\
(\mathrm{kPa})\end{array}$} & \multirow[b]{2}{*}{$\begin{array}{c}\text { Specific } \\
\text { volume } \\
\text { after } \\
\text { consolidation }\end{array}$} & \multicolumn{3}{|c|}{ Ends of test } \\
\hline & & & & $\begin{array}{c}\text { Deviator } \\
\text { stress } q_{\mathrm{cs}} \\
\quad(\mathrm{kPa})\end{array}$ & $\begin{array}{c}\text { Mean } \\
\text { effective } \\
\text { stress } p_{c s}^{\prime} \\
(\mathrm{kPa})\end{array}$ & $\begin{array}{l}\text { Specific } \\
\text { volume } v_{\mathrm{f}}\end{array}$ \\
\hline UD_01 & 1.839 & 100 & 1.821 & 220.5 & 171.4 & 1.707 \\
\hline UD_02 & 1.841 & 200 & 1.795 & 471.1 & 355.1 & 1.644 \\
\hline UD_03 & 1.859 & 400 & 1.751 & 963.7 & 717.9 & 1.584 \\
\hline UD_04 & 1.845 & 500 & 1.724 & 1447.1 & 998.0 & 1.550 \\
\hline $\begin{array}{l}\text { UD_05 } \\
(\mathrm{OCR}=4)\end{array}$ & 1.831 & 150 & 1.729 & 331.5 & 260.5 & 1.668 \\
\hline $\begin{array}{l}\text { UD_06 } \\
(\mathrm{OCR}=24)\end{array}$ & 1.847 & 25 & 1.750 & 61.3 & 45.2 & 1.776 \\
\hline UD_07 & 1.853 & 510 & 1.729 & 1289.0 & 937.8 & 1.575 \\
\hline UD_08† & 1.849 & 510 & 1.728 & 1326.2 & 952.0 & 1.575 \\
\hline UU_01 & 1.851 & 100 & 1.824 & 46.0 & 32.4 & 1.824 \\
\hline UU_02 & 1.852 & 300 & 1.773 & 64.4 & 48.5 & 1.773 \\
\hline UU_03 & 1.848 & 50 & 1.830 & 34.5 & 24.5 & 1.830 \\
\hline UU_04 & 1.850 & 400 & 1.760 & 95.4 & 68.6 & 1.760 \\
\hline UU_05 & 1.851 & 16 & 1.847 & 19.6 & 14.3 & 1.847 \\
\hline UU_06 $†$ & 1.840 & 300 & 1.780 & 71.5 & 52.9 & 1.780 \\
\hline RD_01 & 1.735 & 700 & 1.604 & 1696.0 & 1241.6 & 1.512 \\
\hline RD_02 & 1.639 & 200 & 1.606 & 496.0 & 367.0 & 1.591 \\
\hline RD_03 & 1.778 & 200 & 1.692 & 480.0 & 357.0 & 1.603 \\
\hline RD_04 & 1.853 & 400 & 1.807 & 101.0 & 72.9 & 1.719 \\
\hline RD_05 & 1.546 & 50 & 1.535 & 154.0 & 101.0 & 1.599 \\
\hline RD_06 & 1.883 & 100 & 1.753 & 247.0 & 179.1 & 1.655 \\
\hline $\begin{array}{l}\text { RD_07 } \\
(\mathrm{OCR}=4)\end{array}$ & 1.801 & 150 & 1.626 & 351.0 & 266.0 & 1.597 \\
\hline RD_08 & 1.568 & 530 & 1.526 & 1345.9 & 975.6 & 1.507 \\
\hline RD_09 & 1.873 & 13 & 1.872 & 41.0 & 29.1 & 1.779 \\
\hline RU_01 & 1.743 & 50 & 1.726 & 52.0 & 32.7 & 1.726 \\
\hline RU_02 & 1.604 & 620 & 1.545 & 879.0 & 625.7 & 1.545 \\
\hline RU_03 & 1.535 & 425 & 1.497 & 1446.0 & 1068.0 & 1.497 \\
\hline RU_04 & 1.847 & 600 & 1.634 & 340.0 & 251.0 & 1.634 \\
\hline RU_05 & 1.836 & 550 & 1.622 & 324.0 & 233.0 & 1.622 \\
\hline RU_06 & 1.854 & 16 & 1.840 & 7.0 & 5.1 & 1.840 \\
\hline
\end{tabular}

Note: $\mathbf{R} * * *$ reconstituted, $\mathbf{U} * * *$ undisturbed, $* \mathbf{D} * * *$ drained, $* \mathbf{U}^{* * *}$ undrained, $\dagger$ Horizontal samples, OCR overconsolidation ratio 


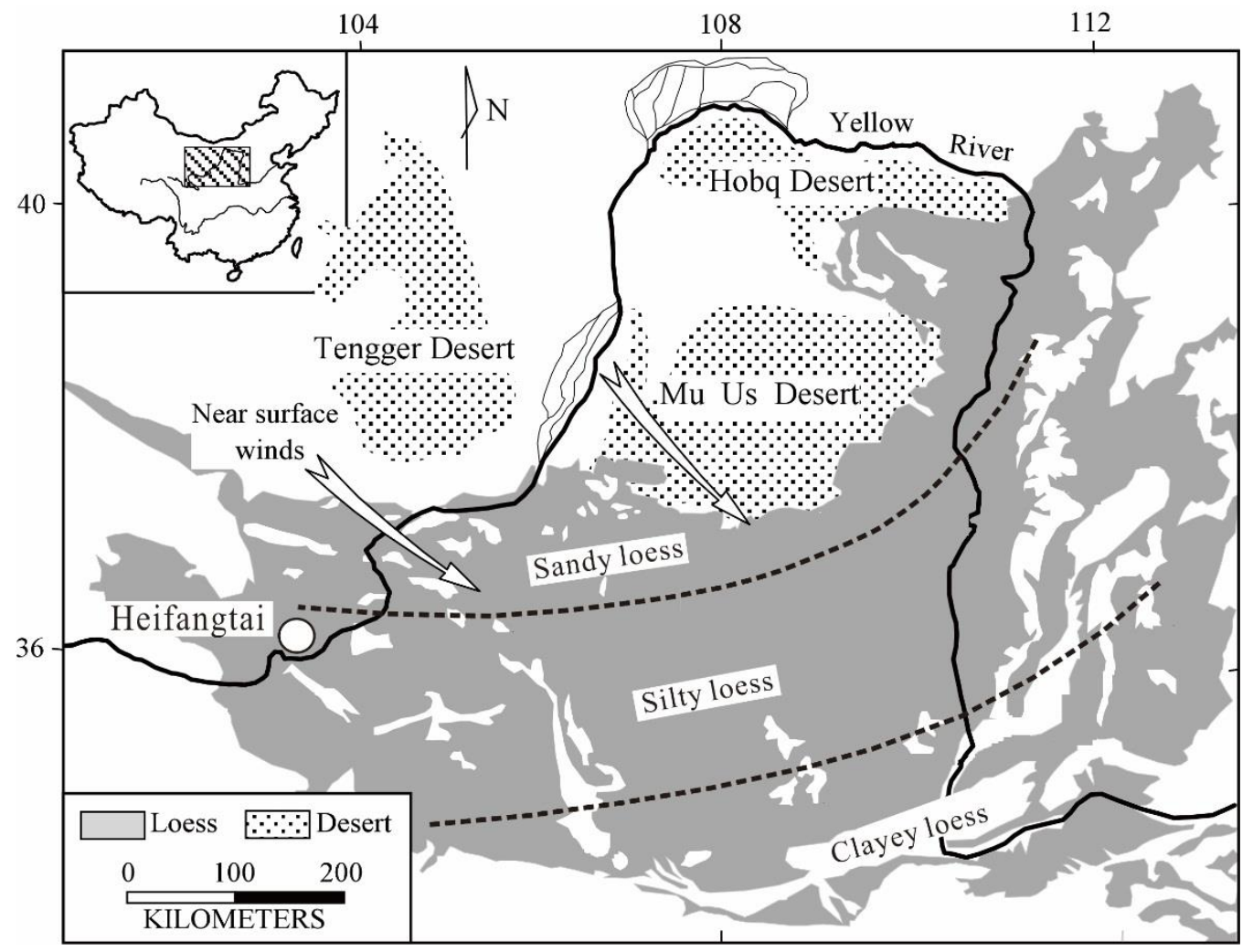

Fig.1. Sample location of Heifangtai on the Chinese Loess Plateau 


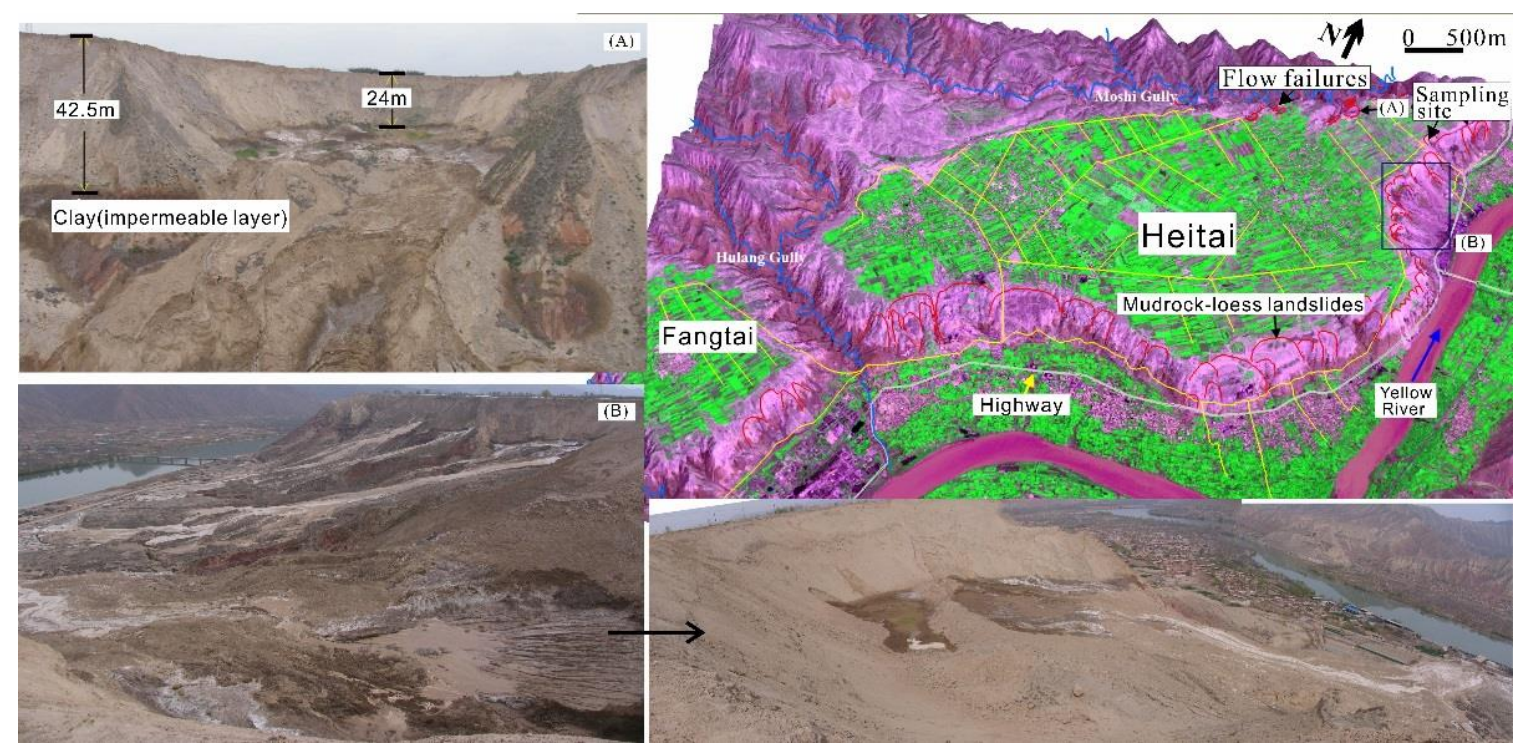

Fig.2. Site description and landslides 


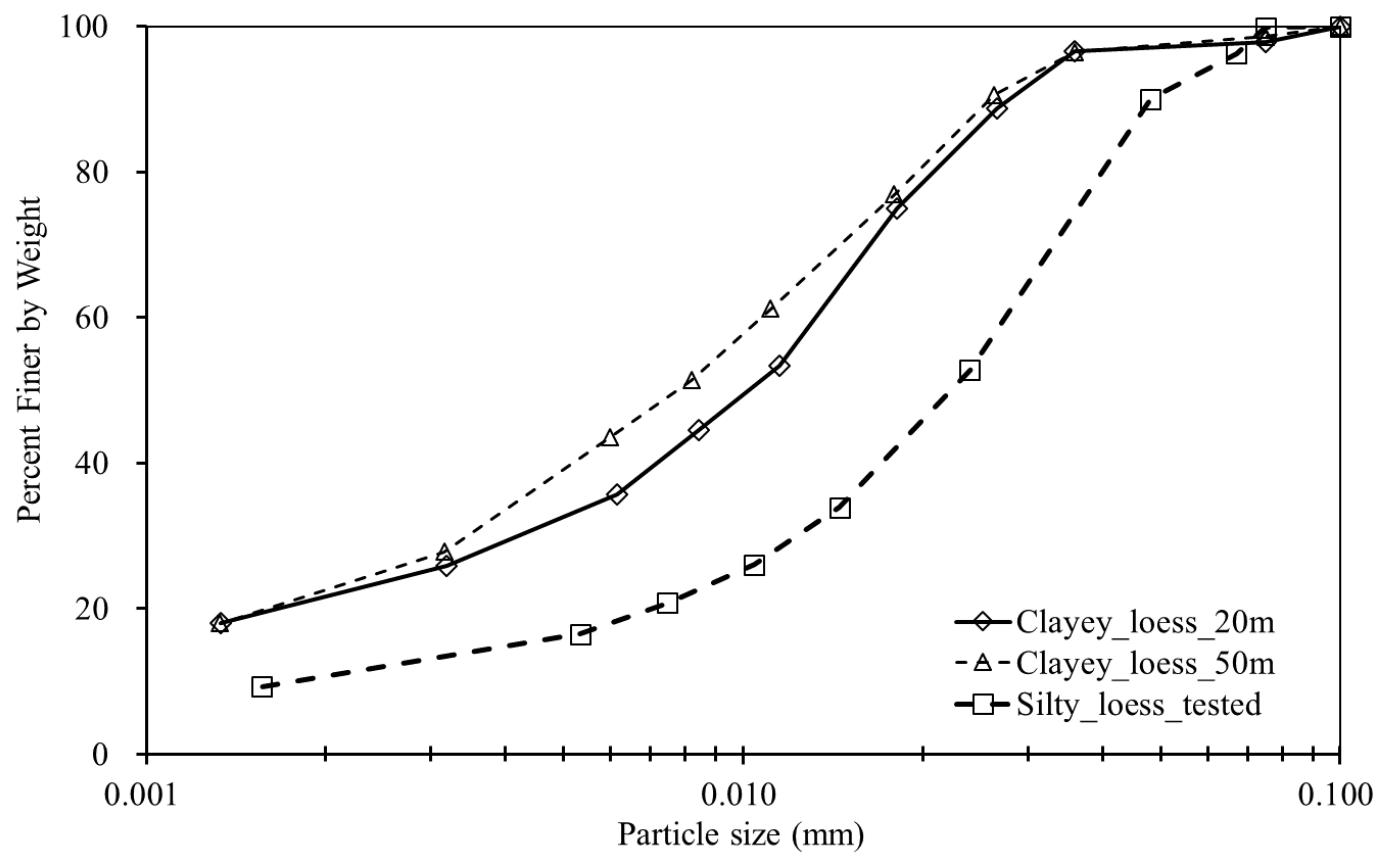

Fig.3. Particle size distributions of the loess samples 


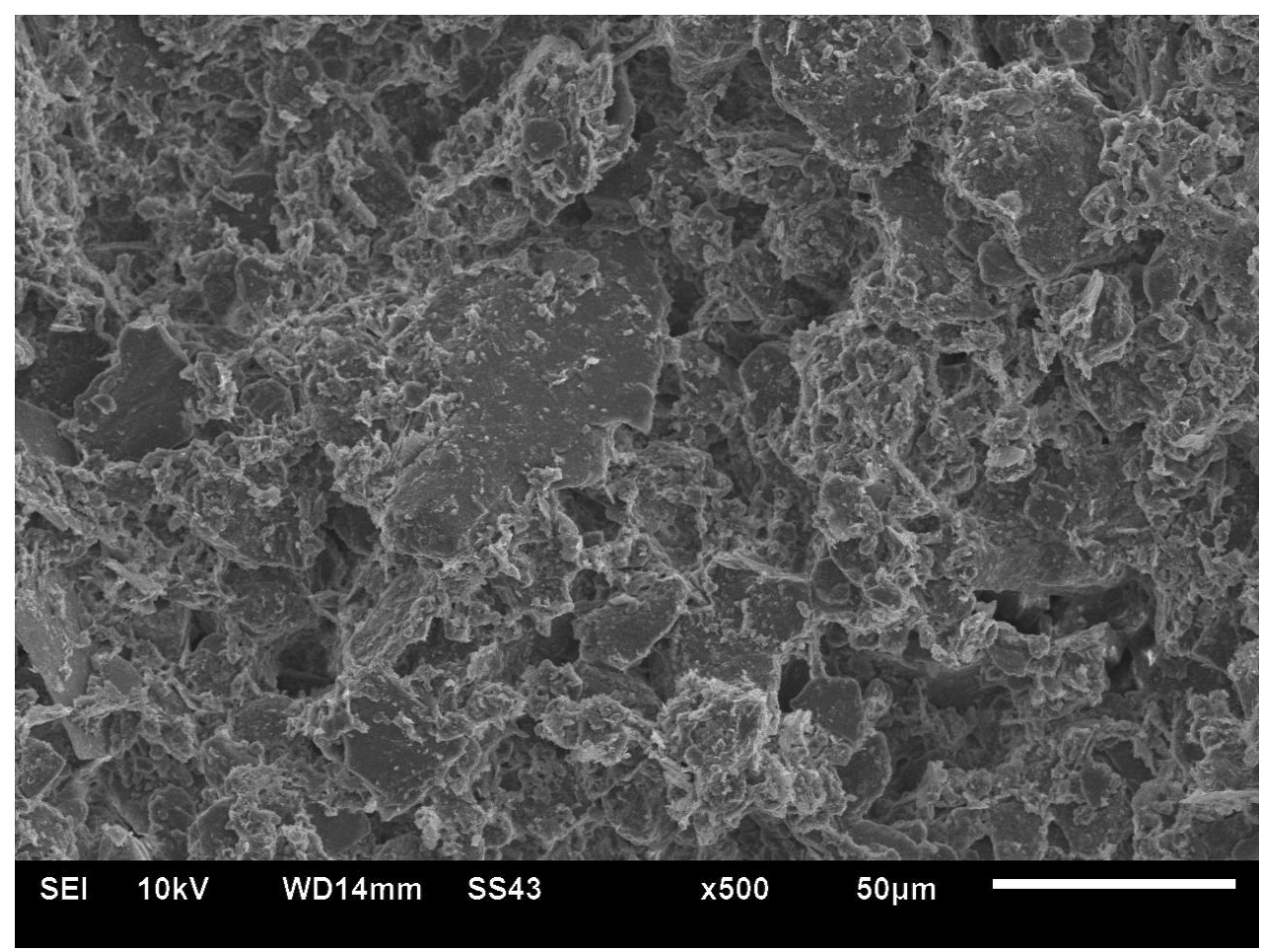

(a) Horizontal plane

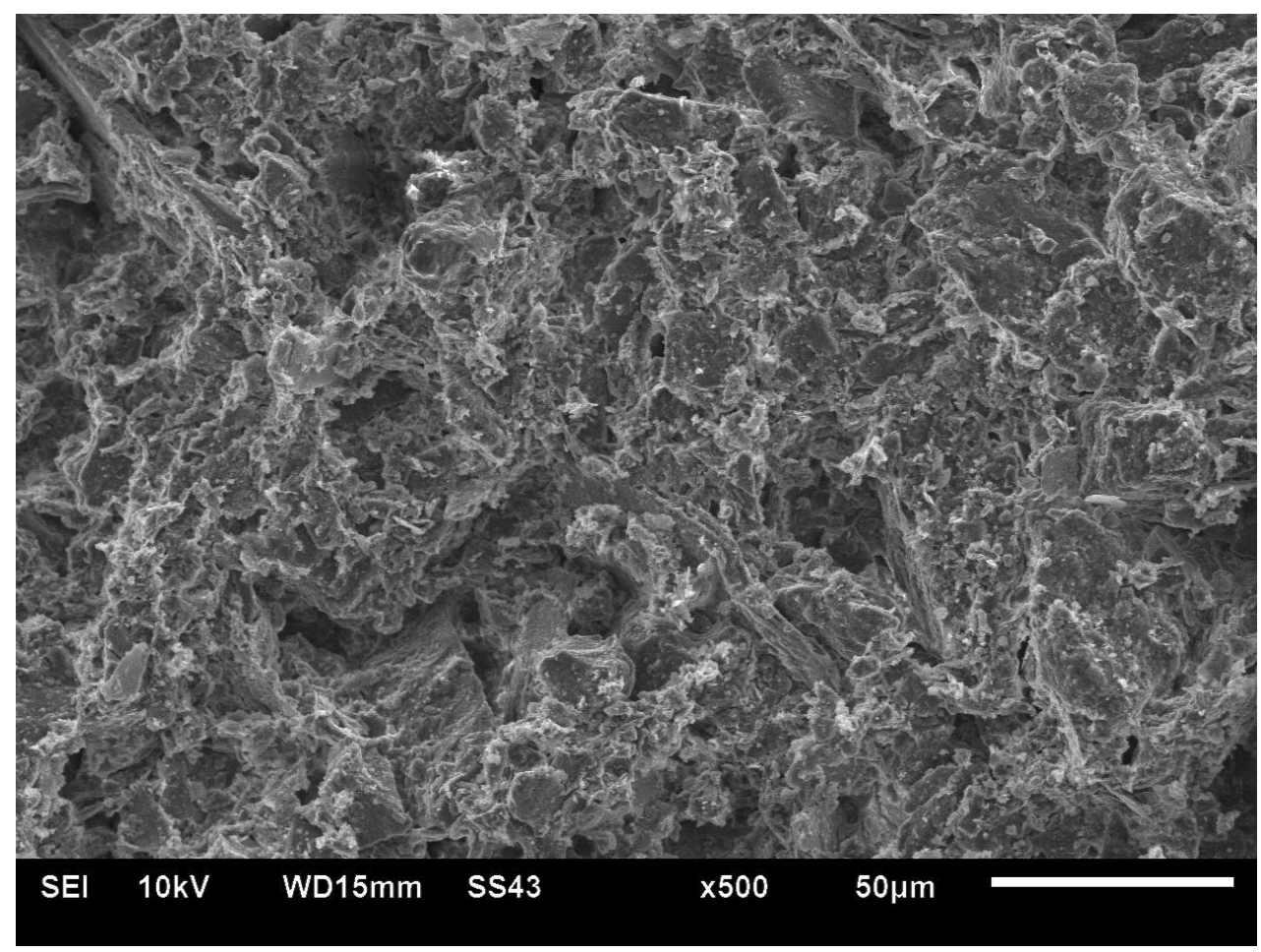

(b) Vertical plane 


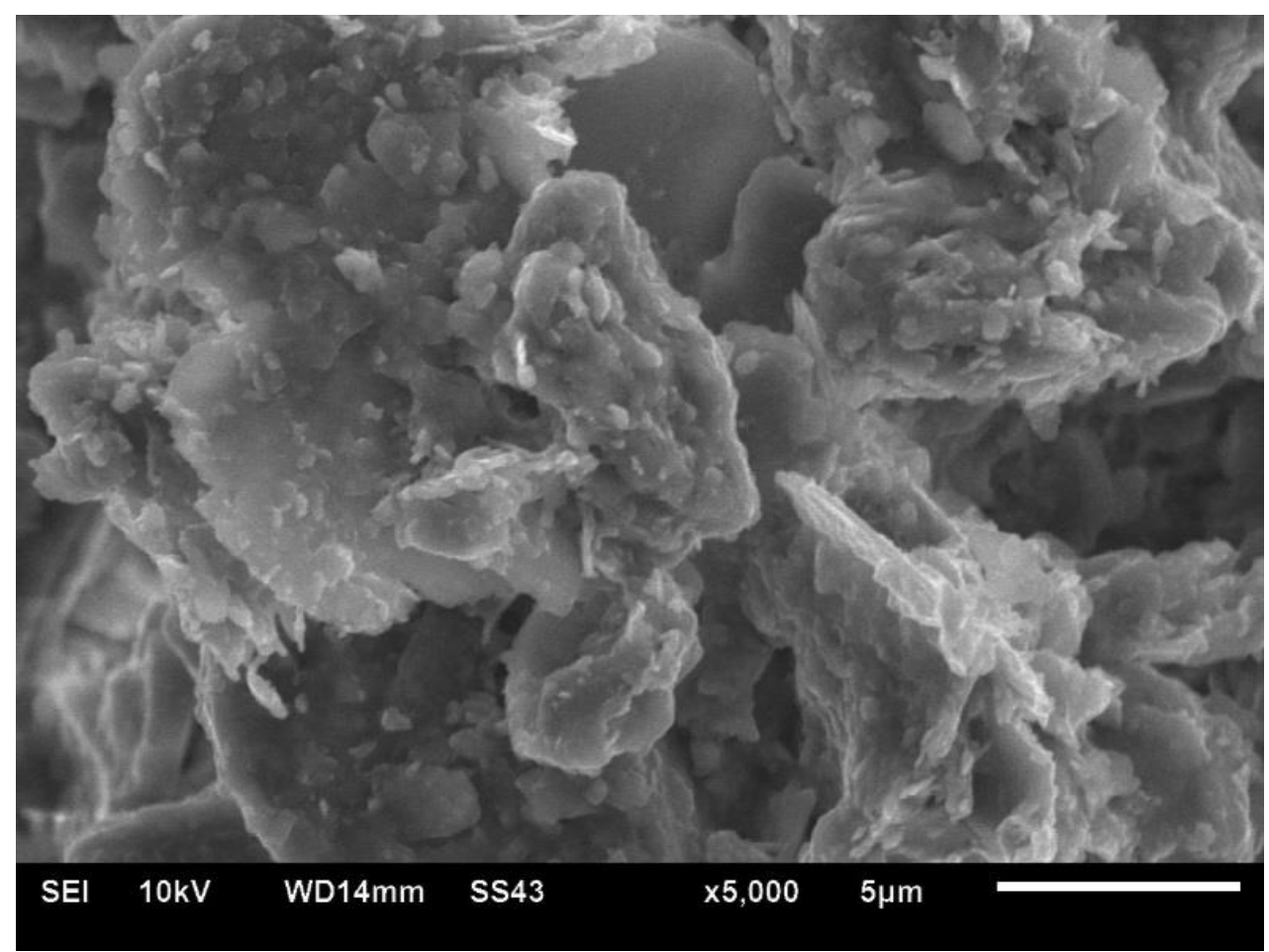

(c) Higher magnification image showing pores between aggregates

Fig.4. SEM images of the intact micro-structure of the loess (a) horizontal plane; (b) vertical plane; (c) higher magnification image showing pores between aggregates 


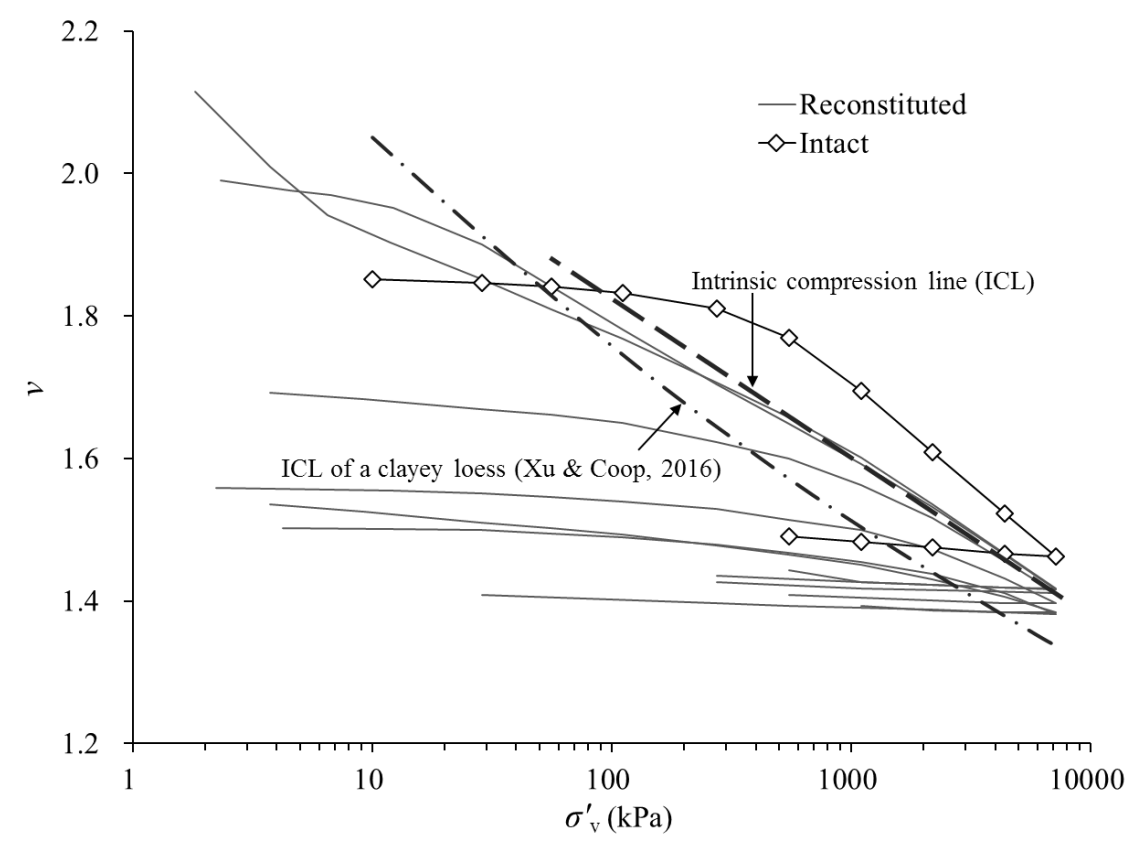

(a)

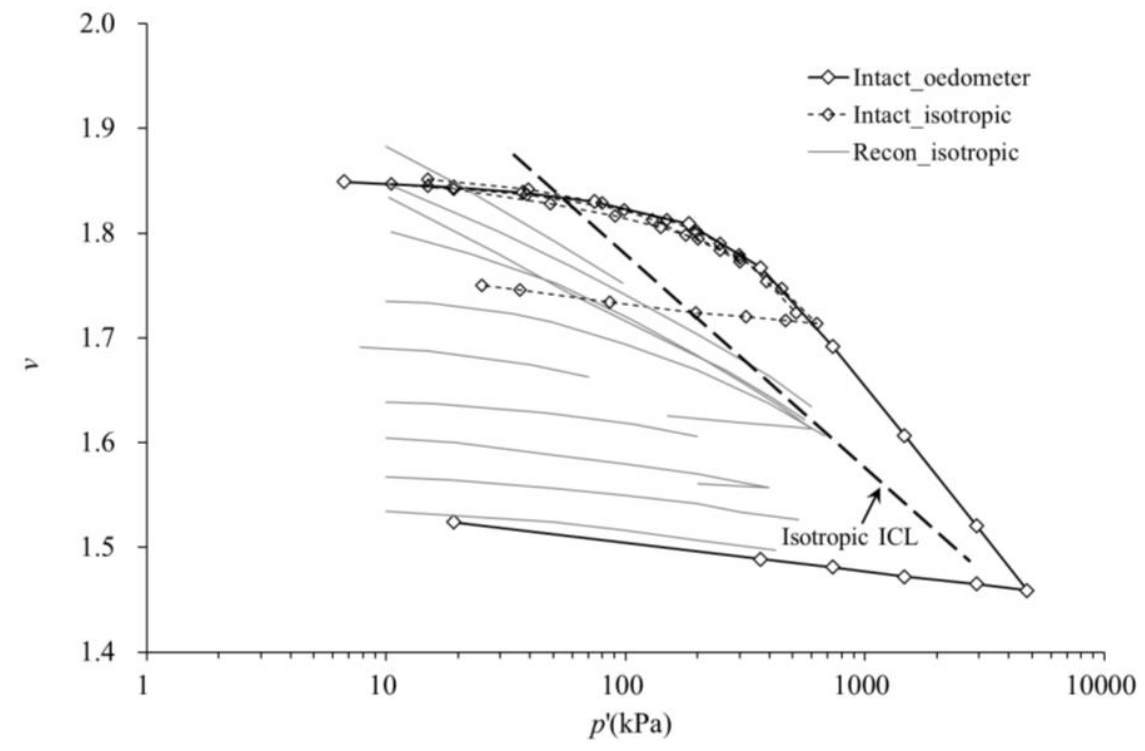

(b)

Fig.5. Compression curves of reconstituted and intact samples: (a) oedometer tests; (b) isotropic compression curves from triaxial tests 


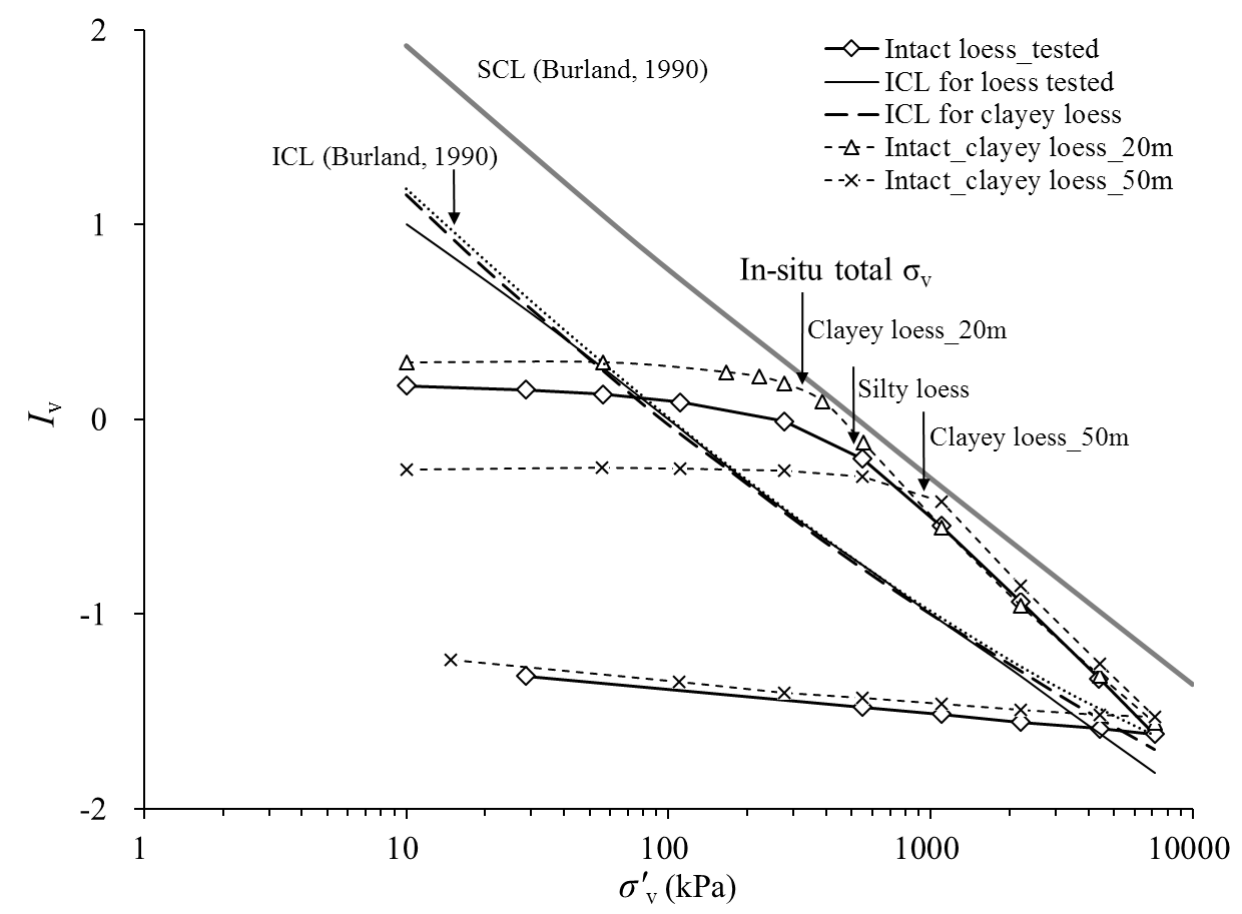

(a)

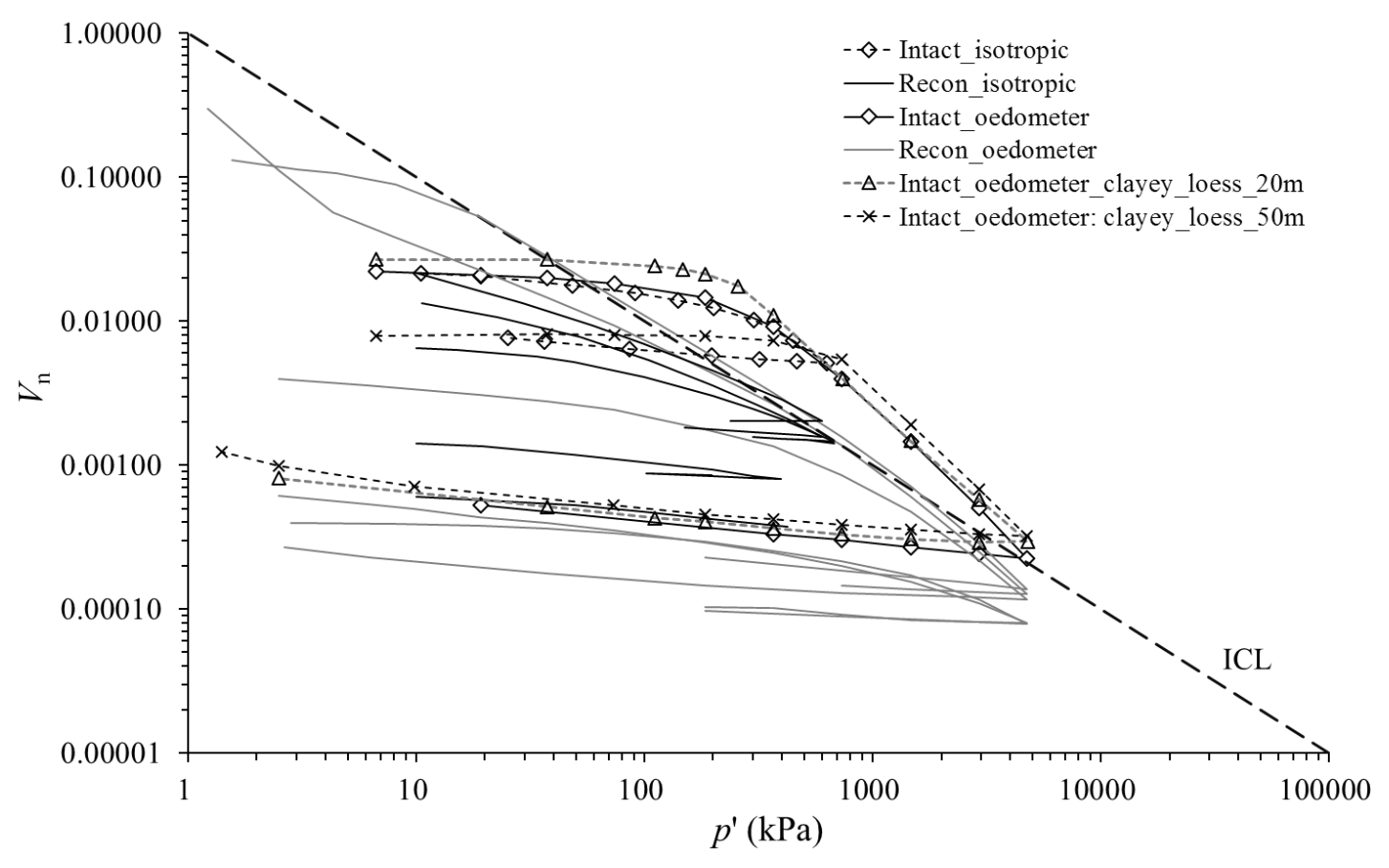

(b)

Fig. 6. Normalized compression data for natural and reconstituted loess (a) using void index, Iv; (b) normalized specific volume, vn 


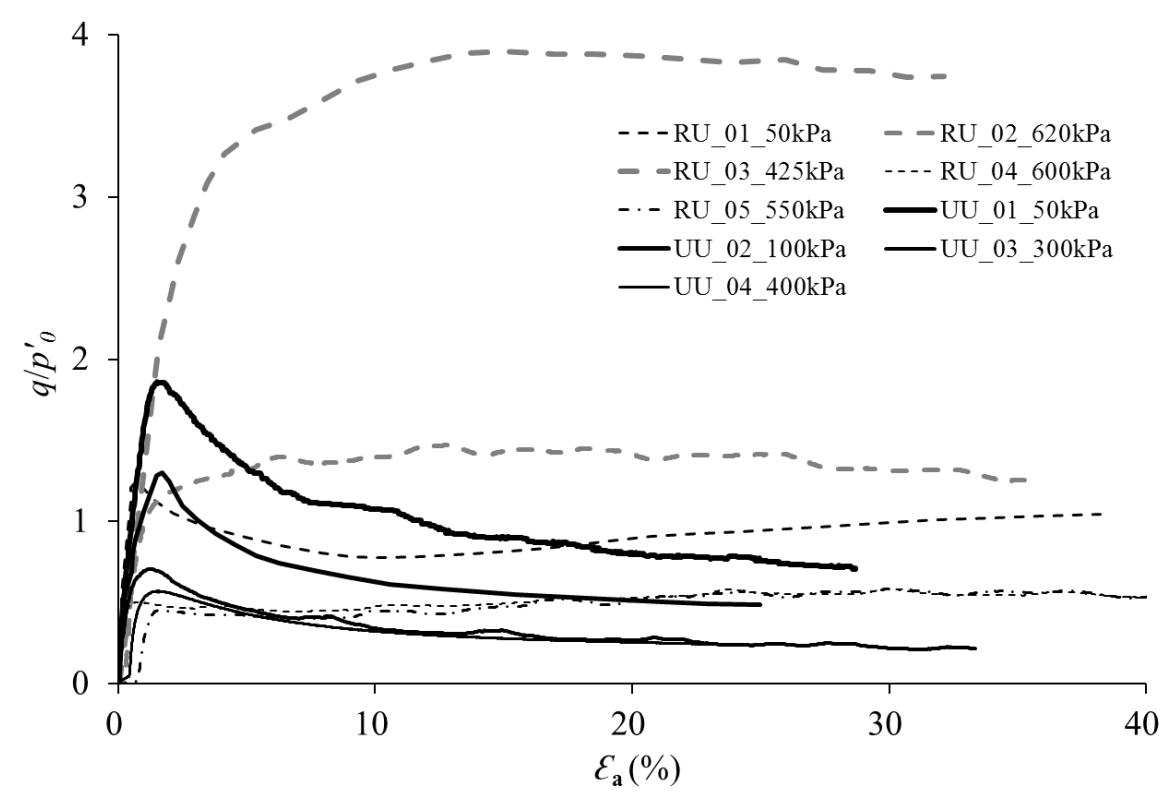

(a)

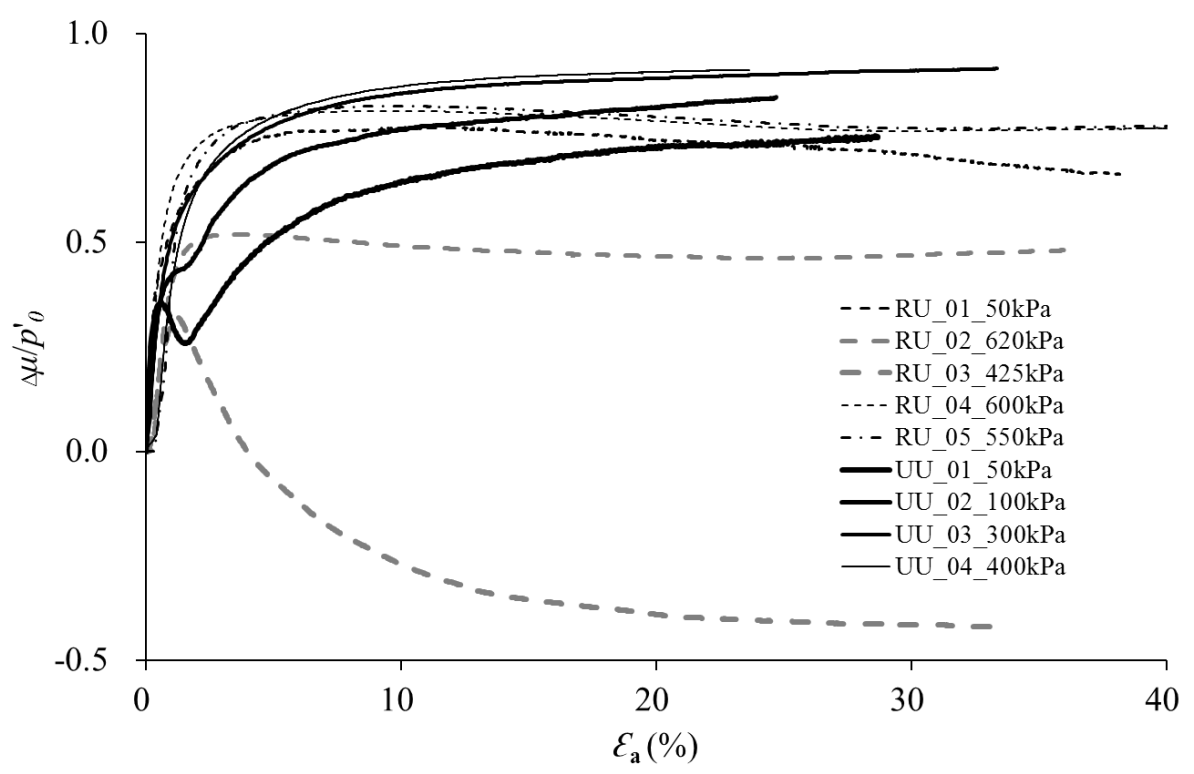

(b)

Fig.7. Typical results of undrained triaxial tests (a) normalized deviator stress-axial strain curves, (b) normalized pore pressure responses $\left(\mathrm{R}^{* * *}\right.$ reconstituted, $\mathrm{U} * * *$ undisturbed, $* \mathrm{D}^{* *}$ drained, ${ }^{*} \mathrm{U}^{* *}$ undrained) 


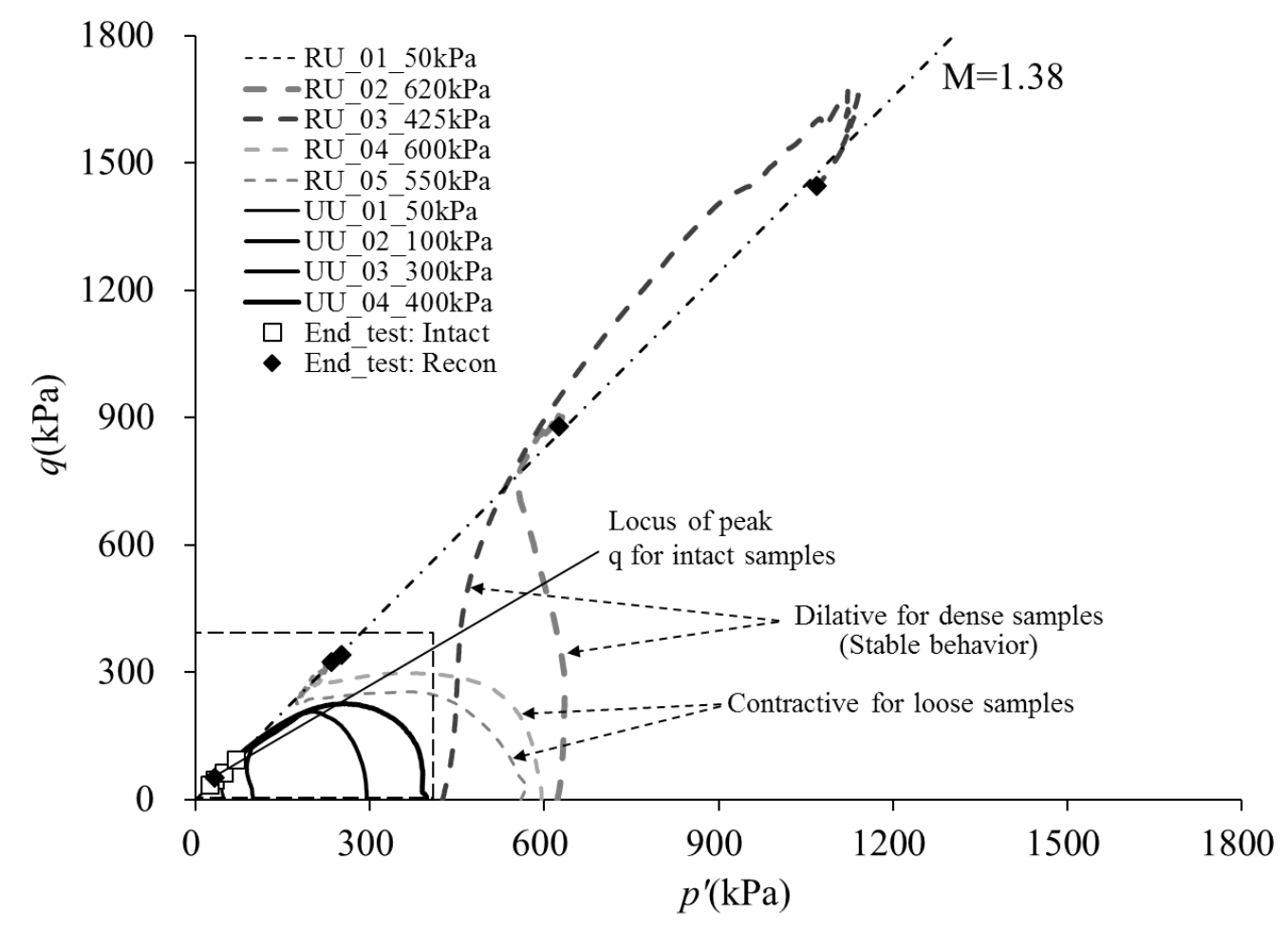

(a)

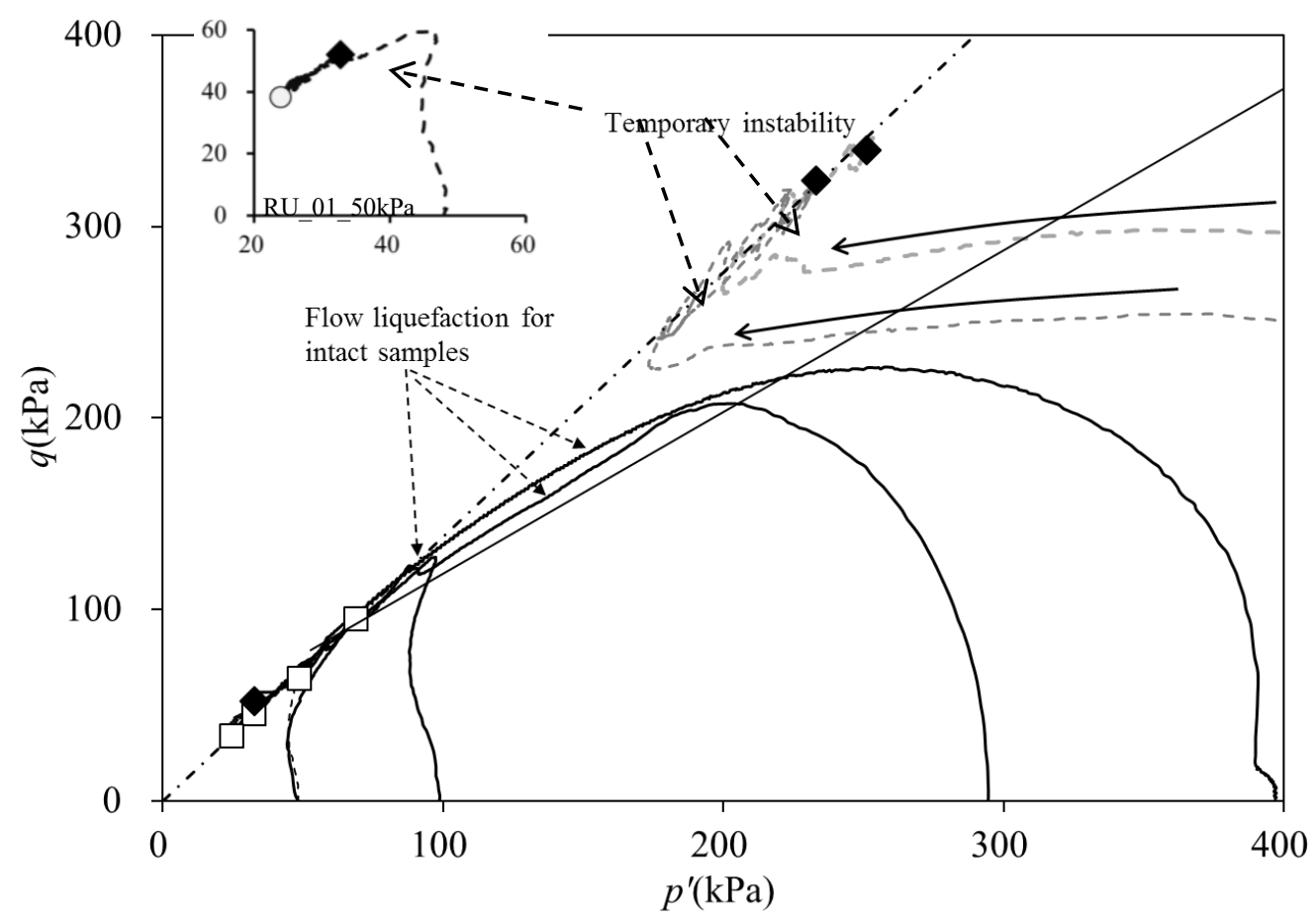

(b)

Fig.8. Stress paths of undrained triaxial tests (a) entire range of stresses; (b) enlargement for stresses less than $400 \mathrm{kPa}$ 


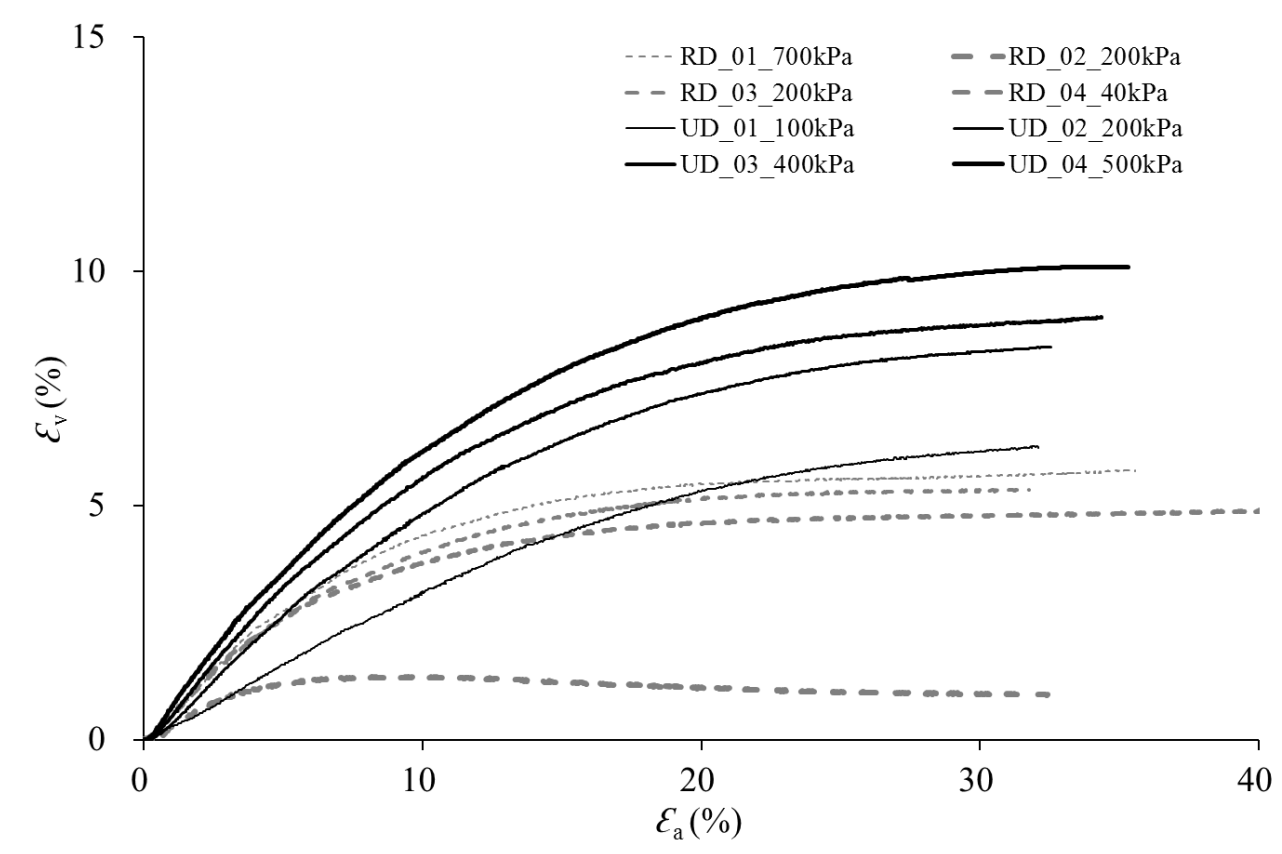

(a)

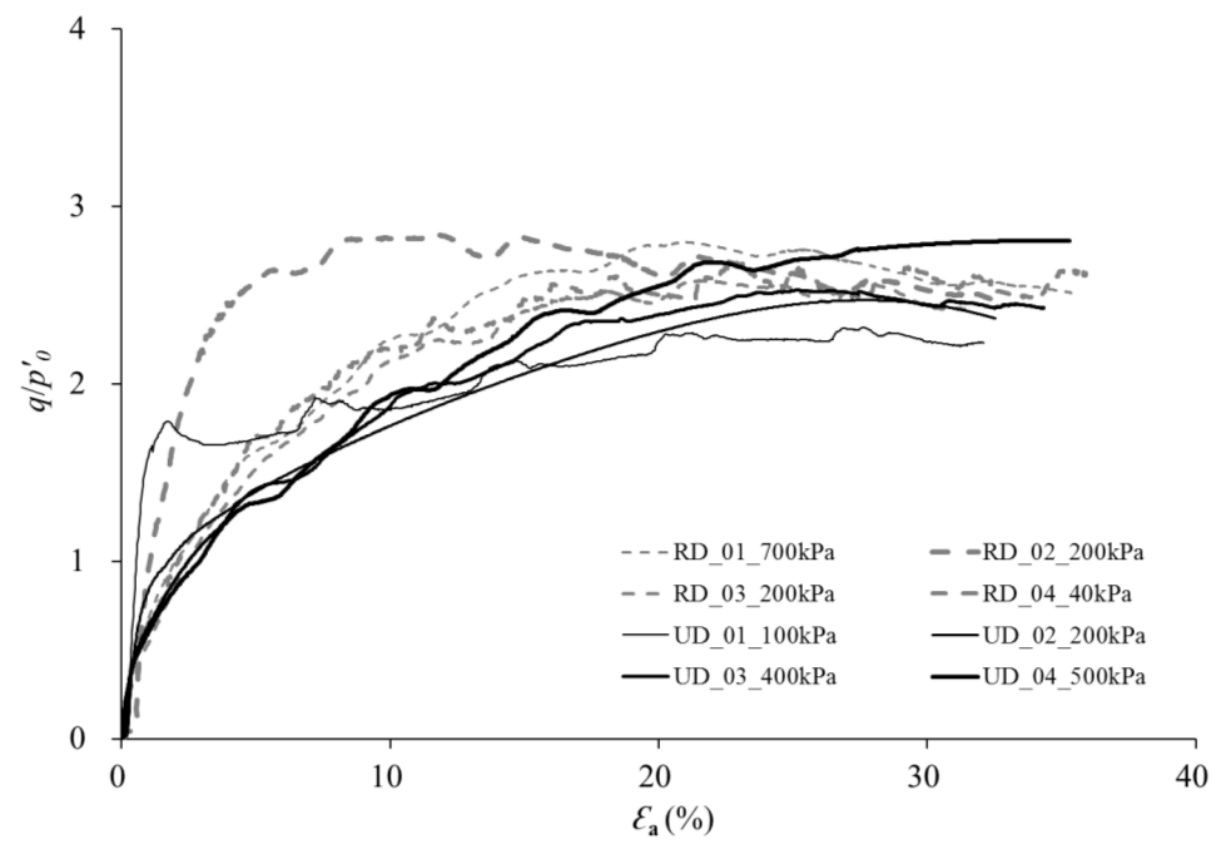

(b) 


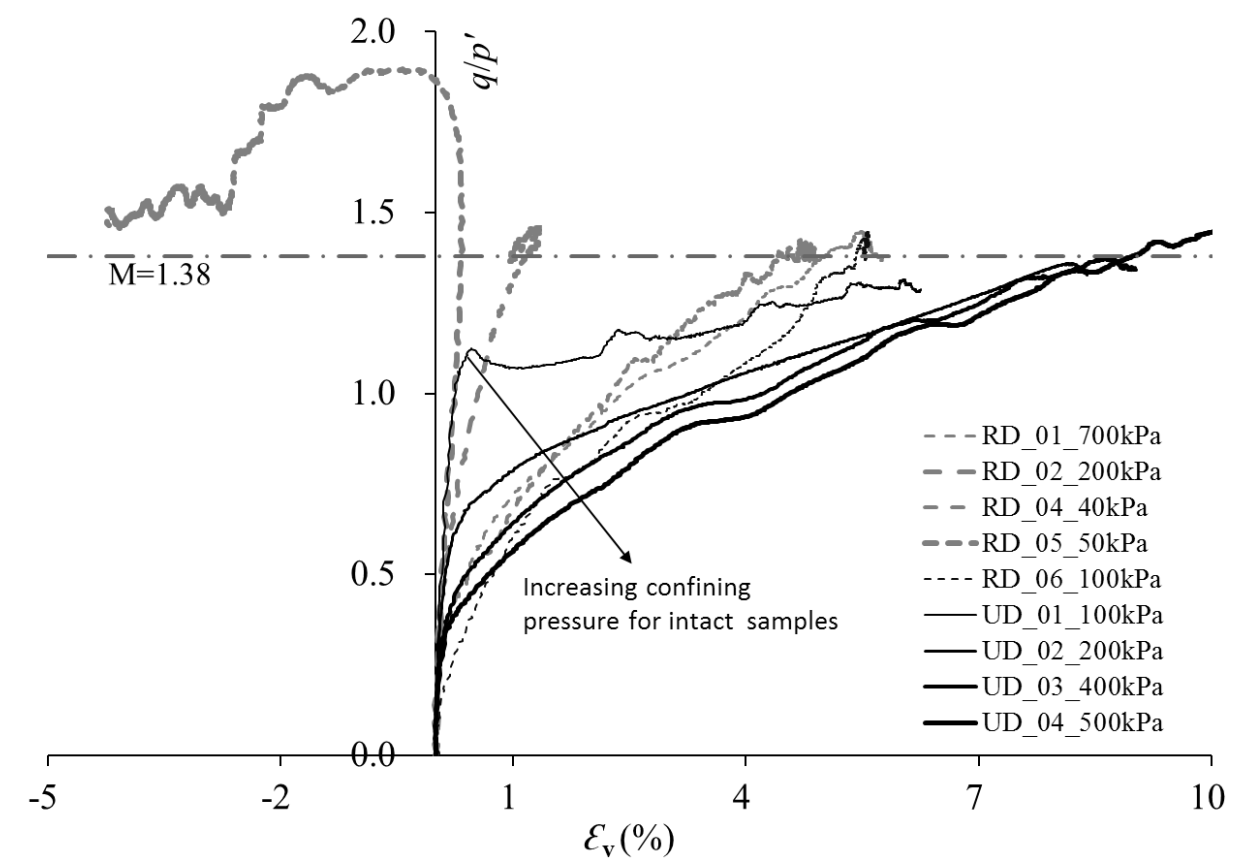

(c)

Fig.9. Typical results of drained triaxial test (a) volume changes-axial strain curves; (b) deviator stress-axial strain curves; (c) stress ratio-volume strain curves 


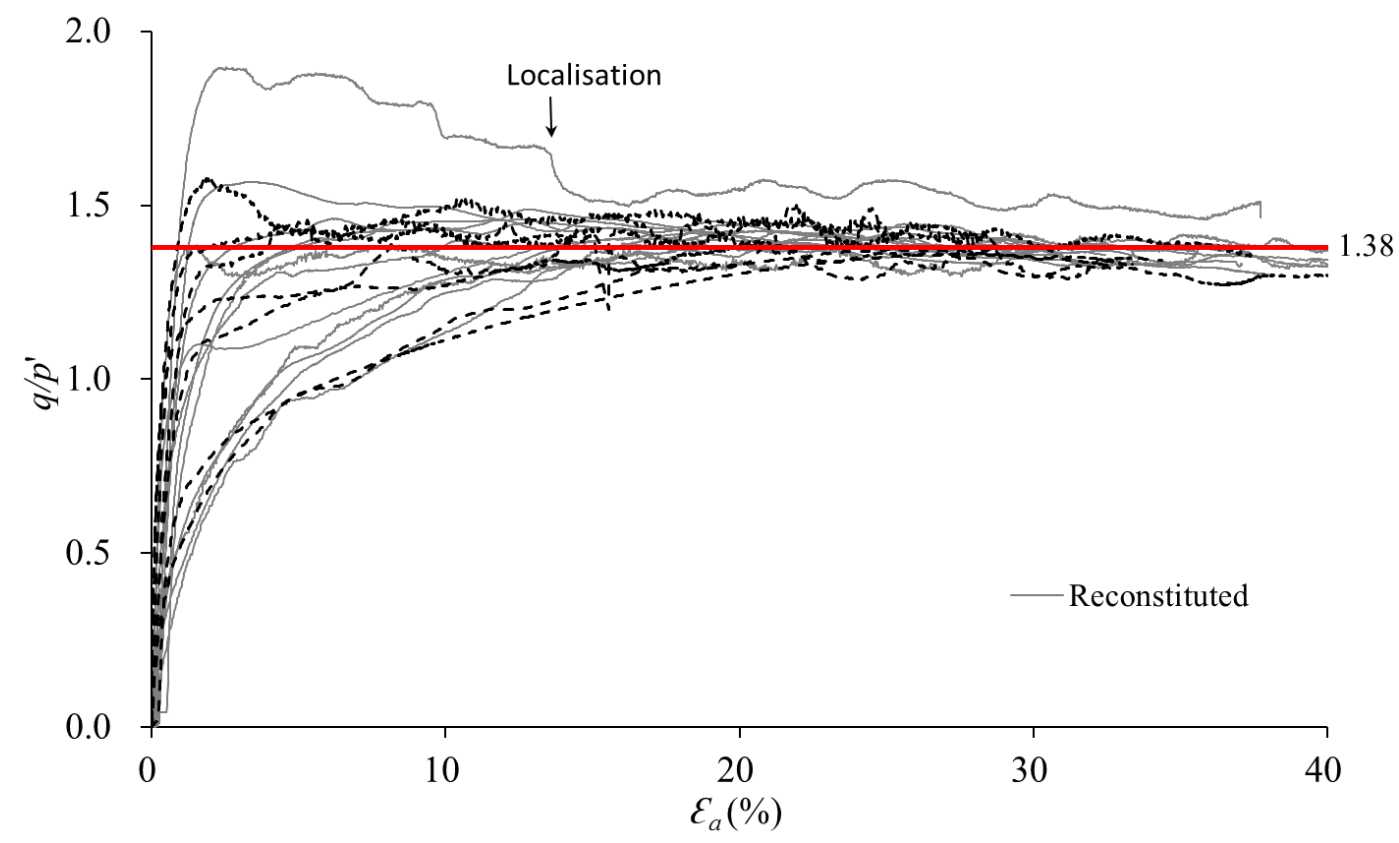

Fig.10. Development of stress ratio for reconstituted and undisturbed specimens 


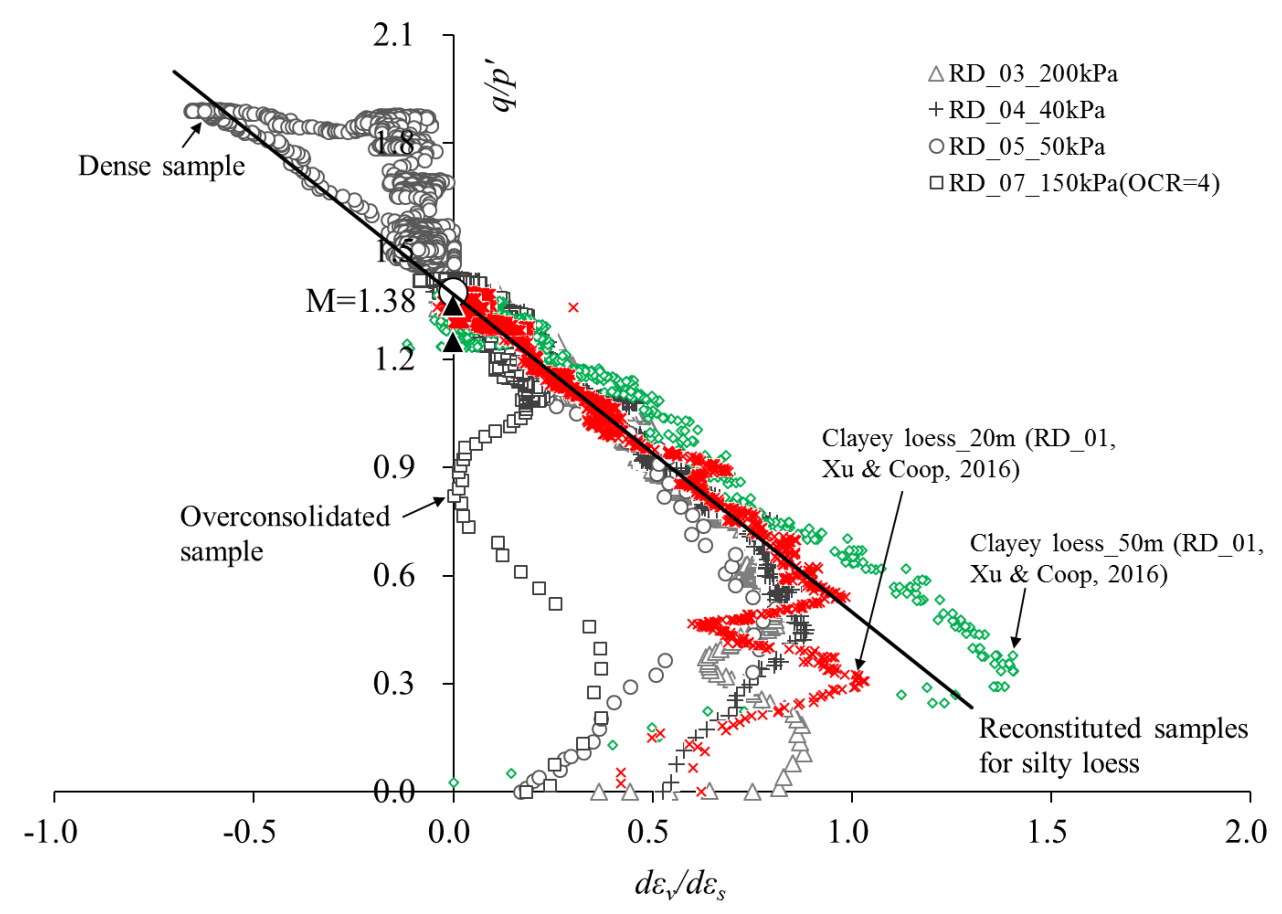

(a)

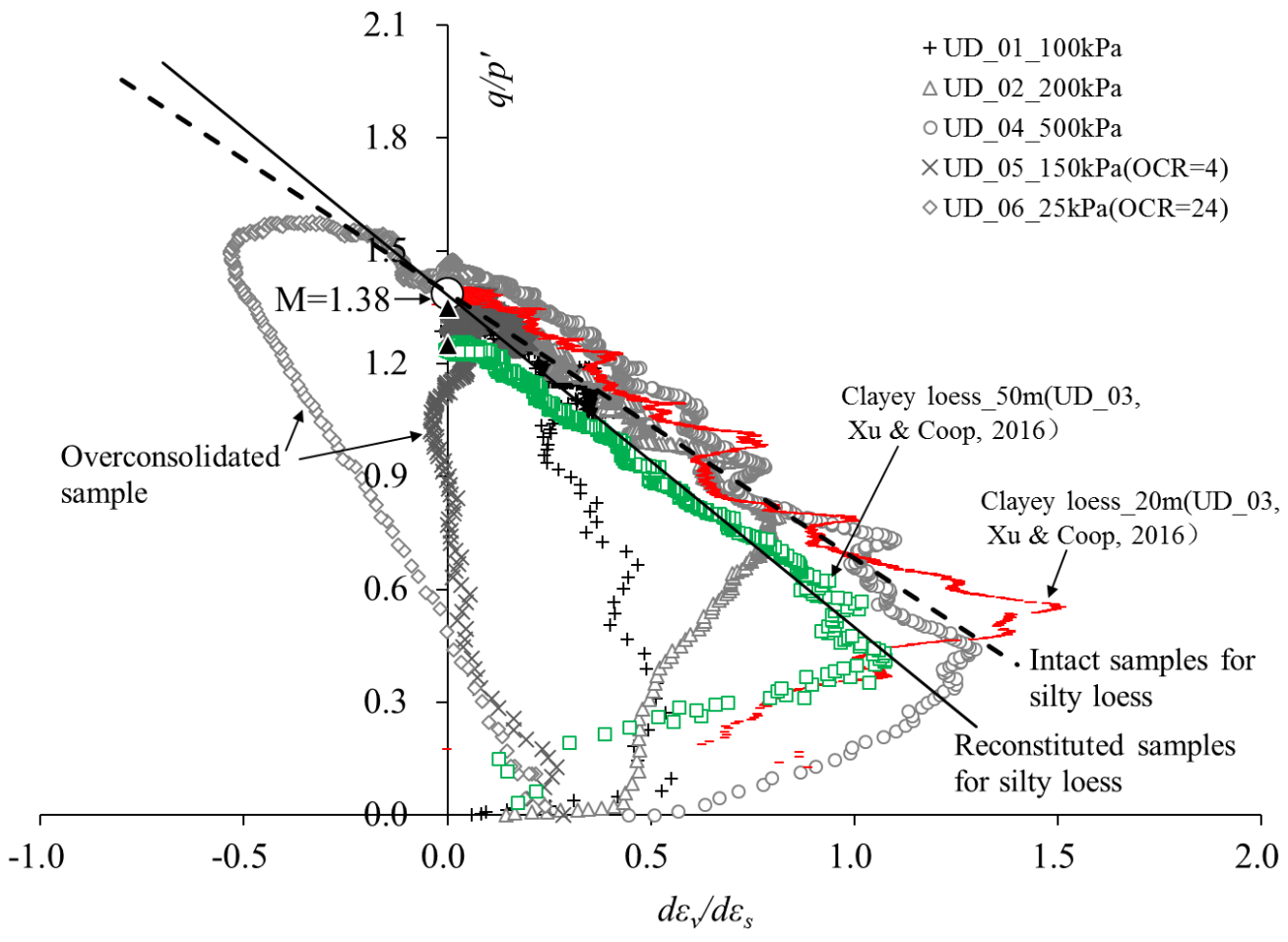

(b)

Fig.11. Stress-dilatancy data for the drained tests on (a) reconstituted specimens; (b) undisturbed specimens 


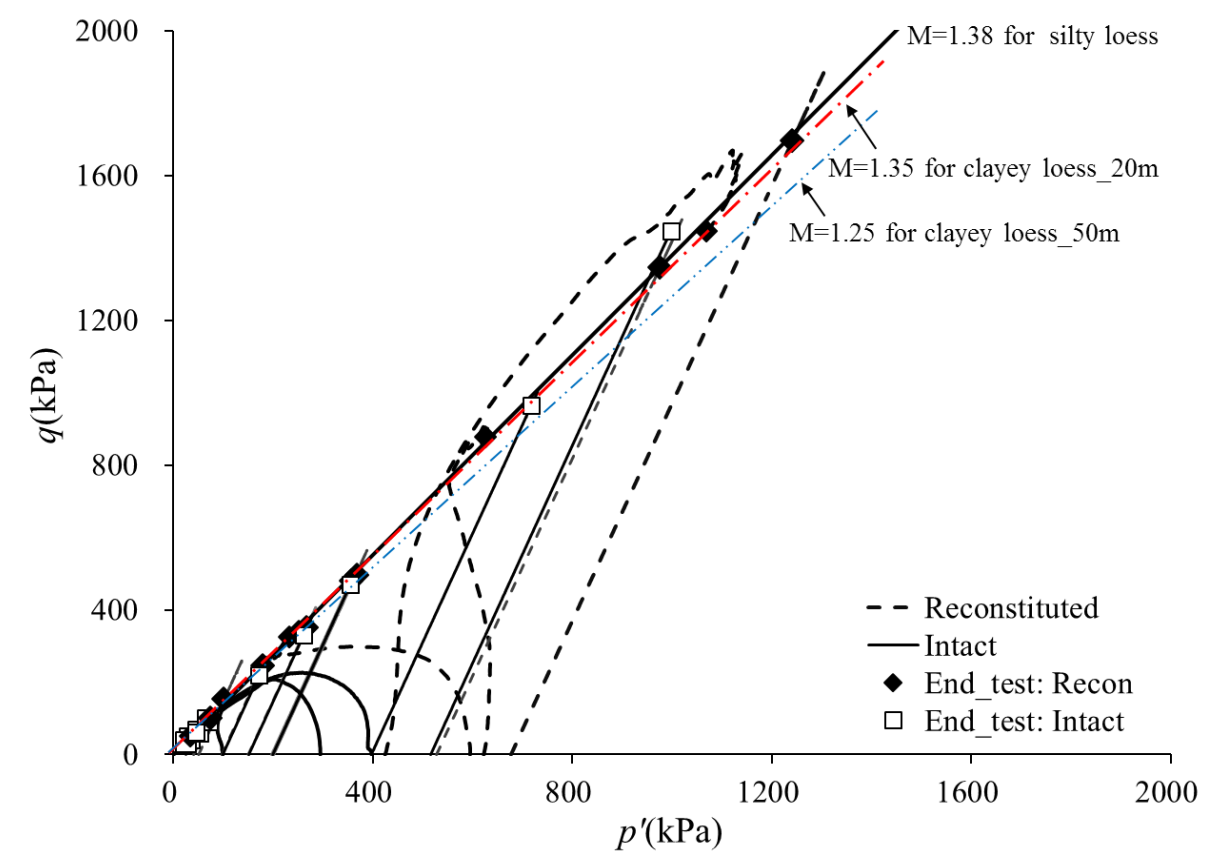

(a)

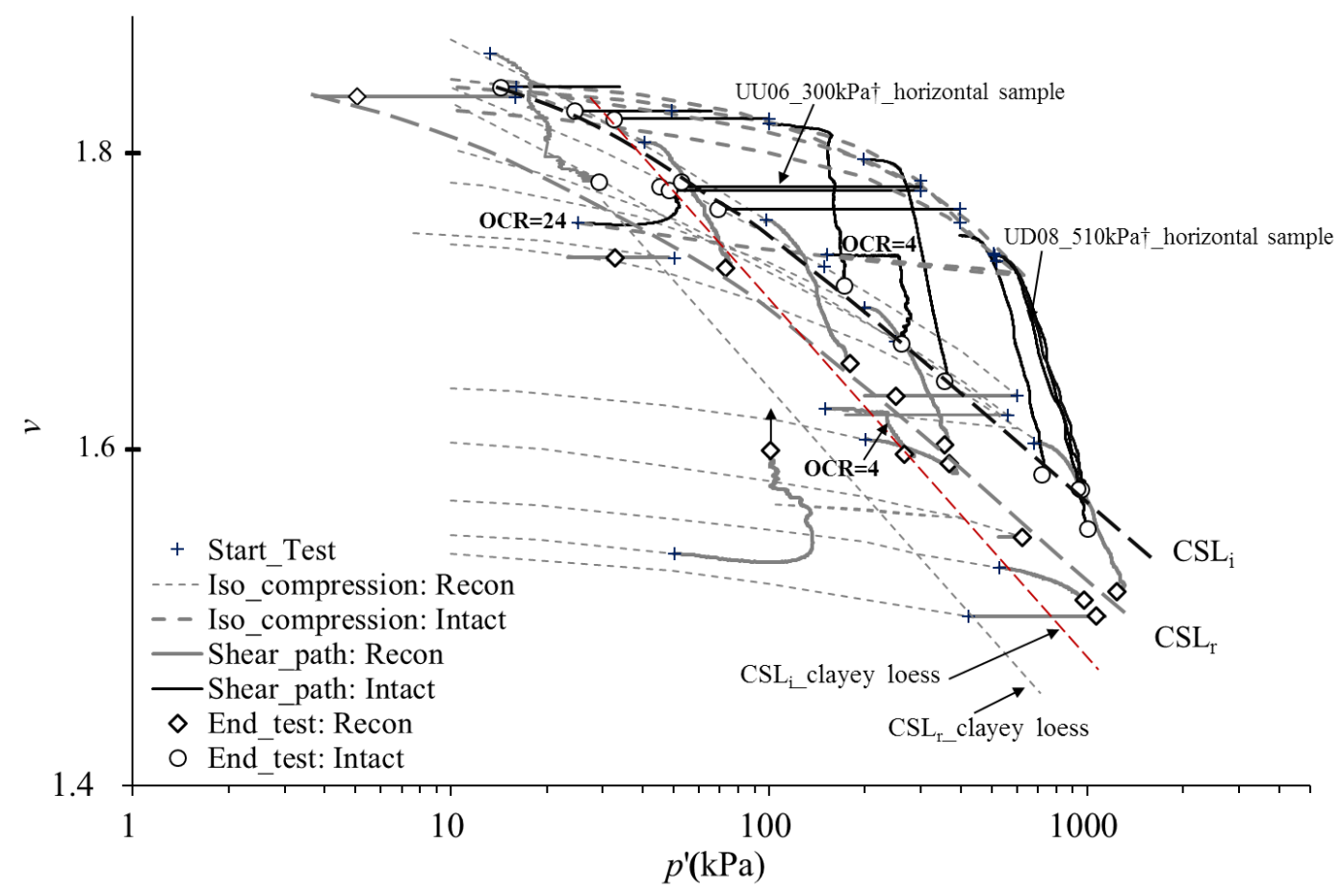

(b)

Fig.12. Critical states line in (a) q-p' space (b) the volumetric plane 


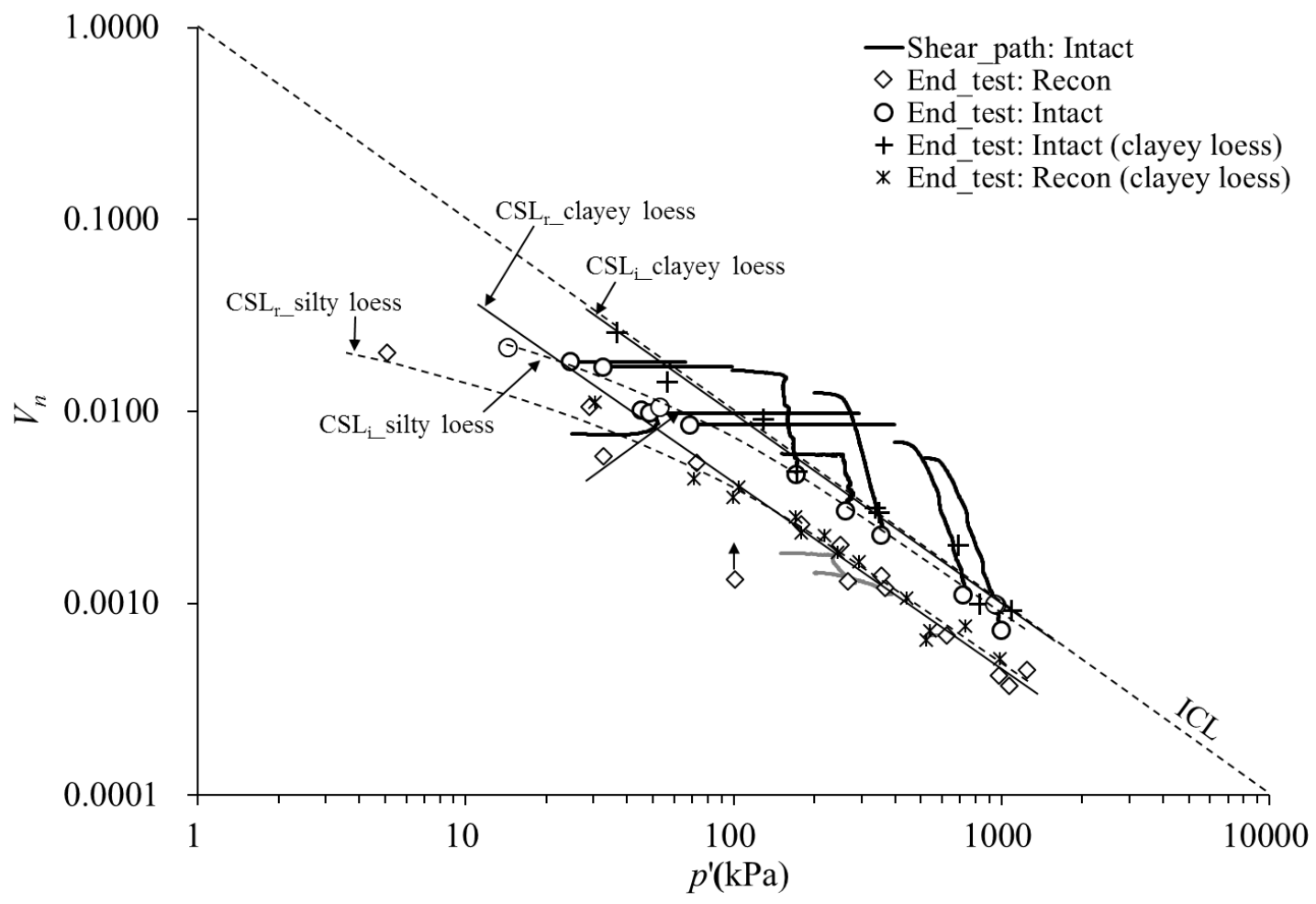

Fig. 13. Critical states line in the normalized volumetric plane 


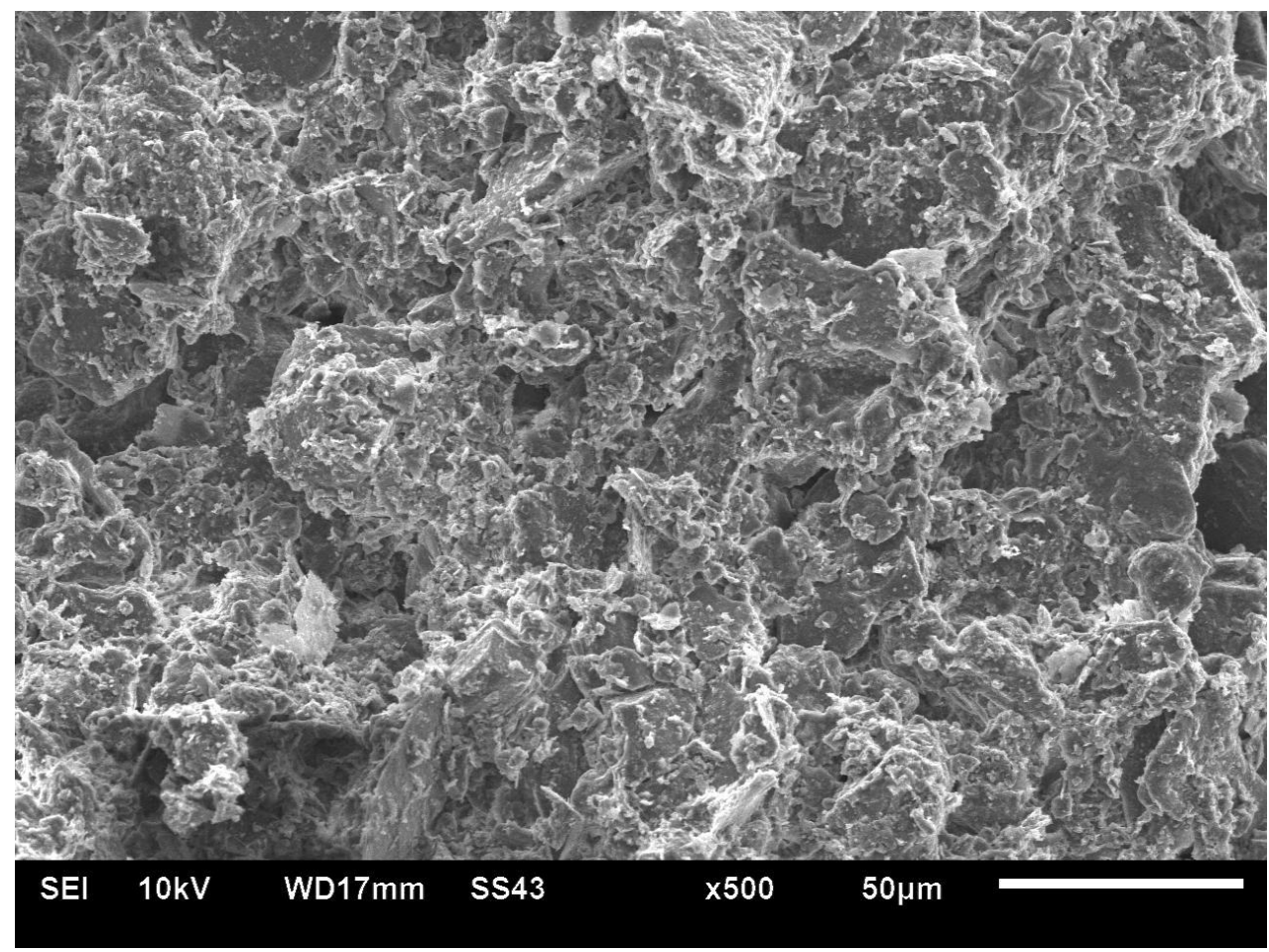

(a) Horizontal plane for sheared intact loess

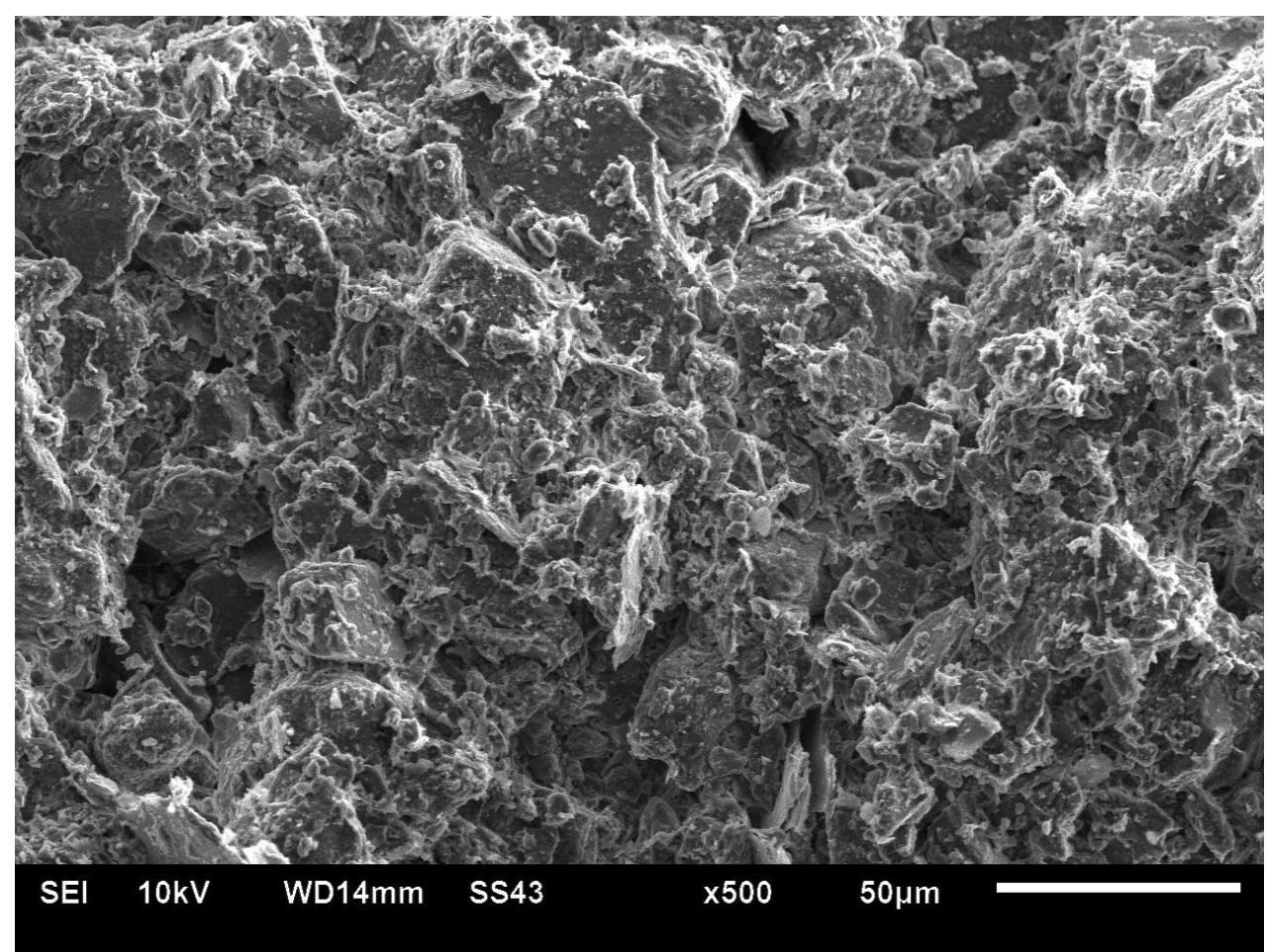

(b) Vertical surface for sheared intact loess 


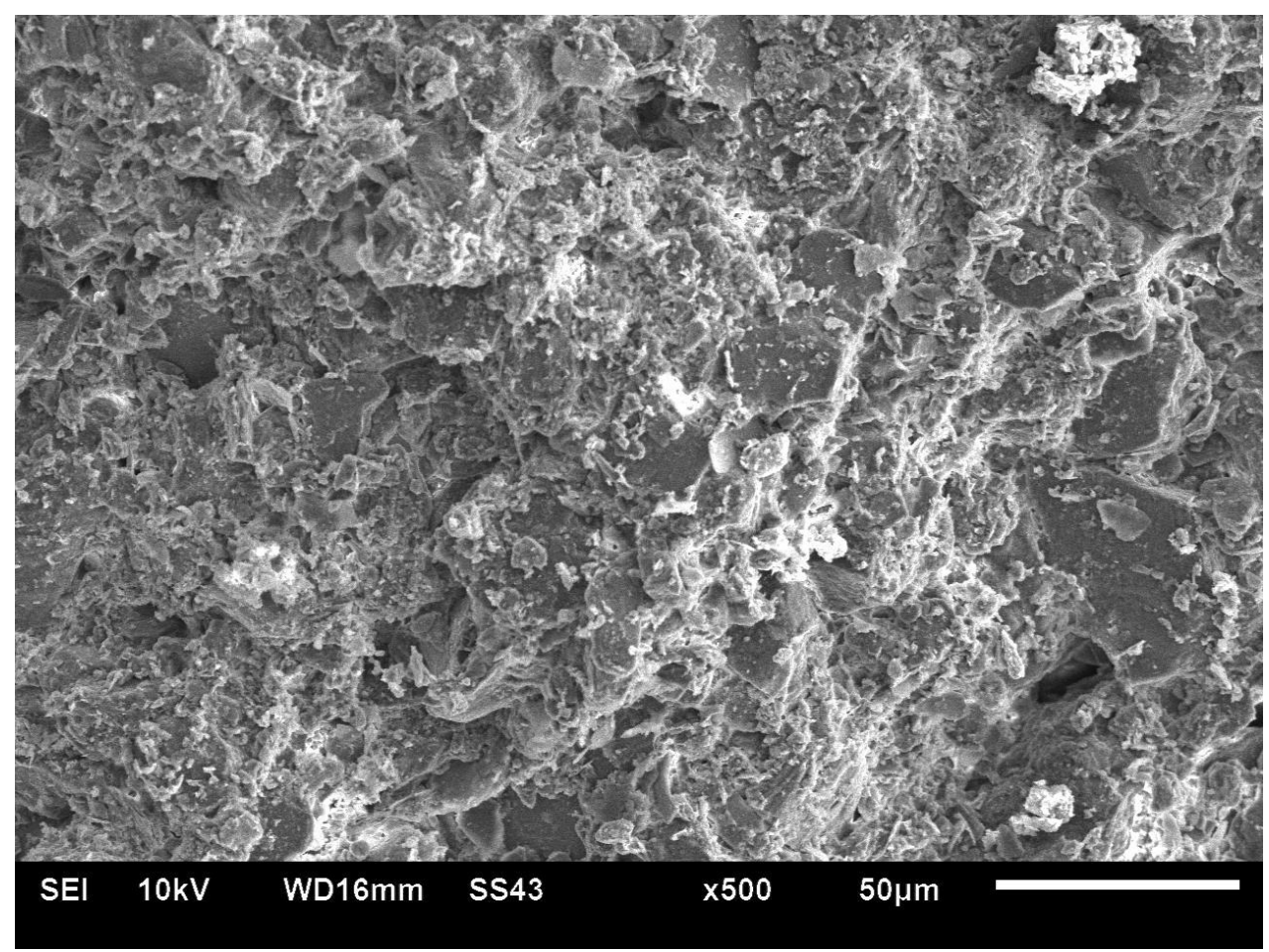

(c) Horiziontal plane for sheared reconstituted loess

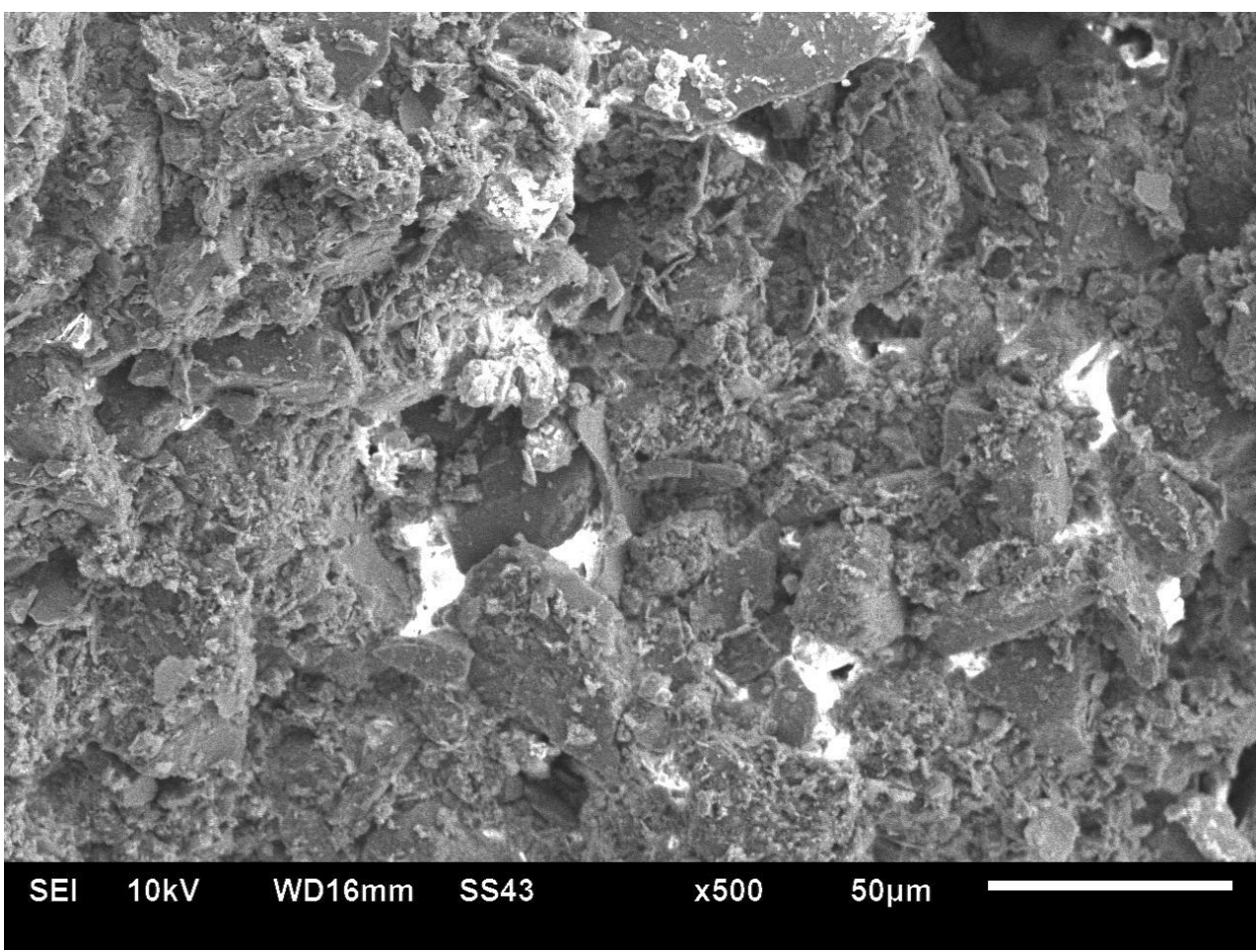

(d) Vertical plane for sheared reconstituted loess 


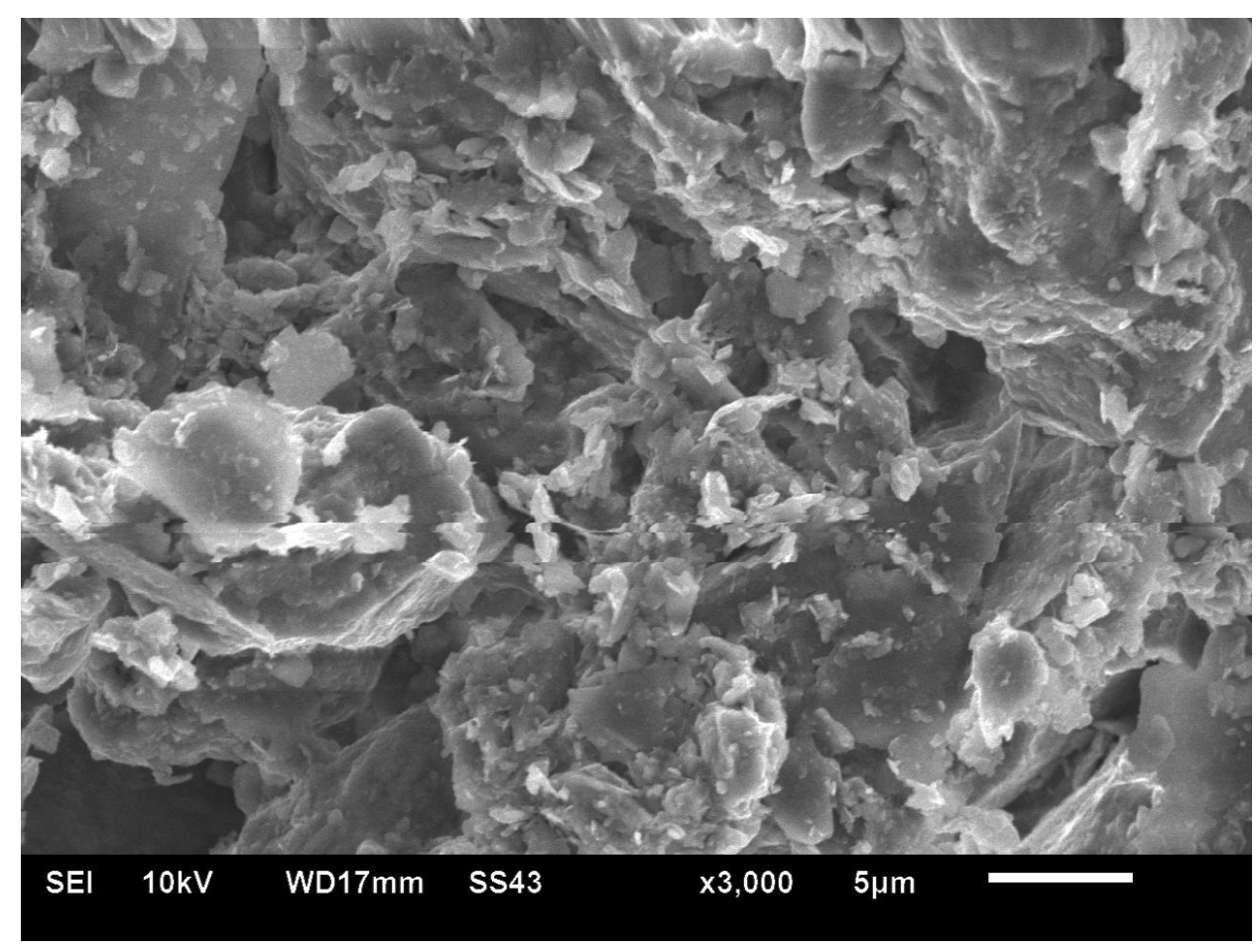

(e) Higher magnification image showing fabric for sheared intact loess

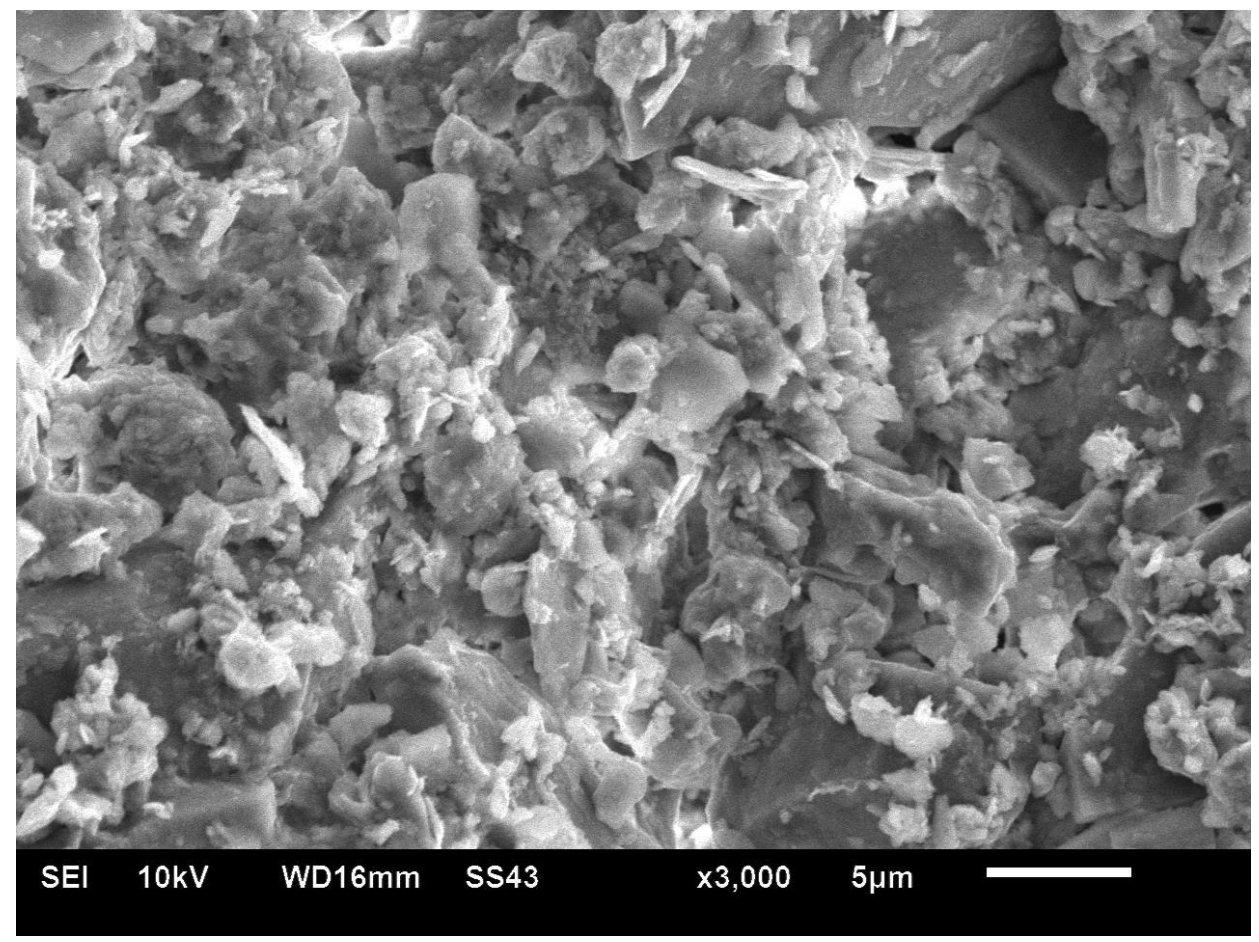

(f) Higher magnification image showing fabric for sheared reconstituted loess 
Fig.14. SEM images of samples after shearing (a) intact sample (No. UD_05) horizontal surface; (b) intact sample (No. UD_05) vertical surface; (c) reconstituted sample (No. RD_07) horizontal surface; (d) reconstituted sample (No. RD_07) vertical surface; (e) higher magnification image for intact sample (No. UD_05) horizontal surface; (f) higher magnification image for reconstituted sample (No. RD_07) horizontal surface 


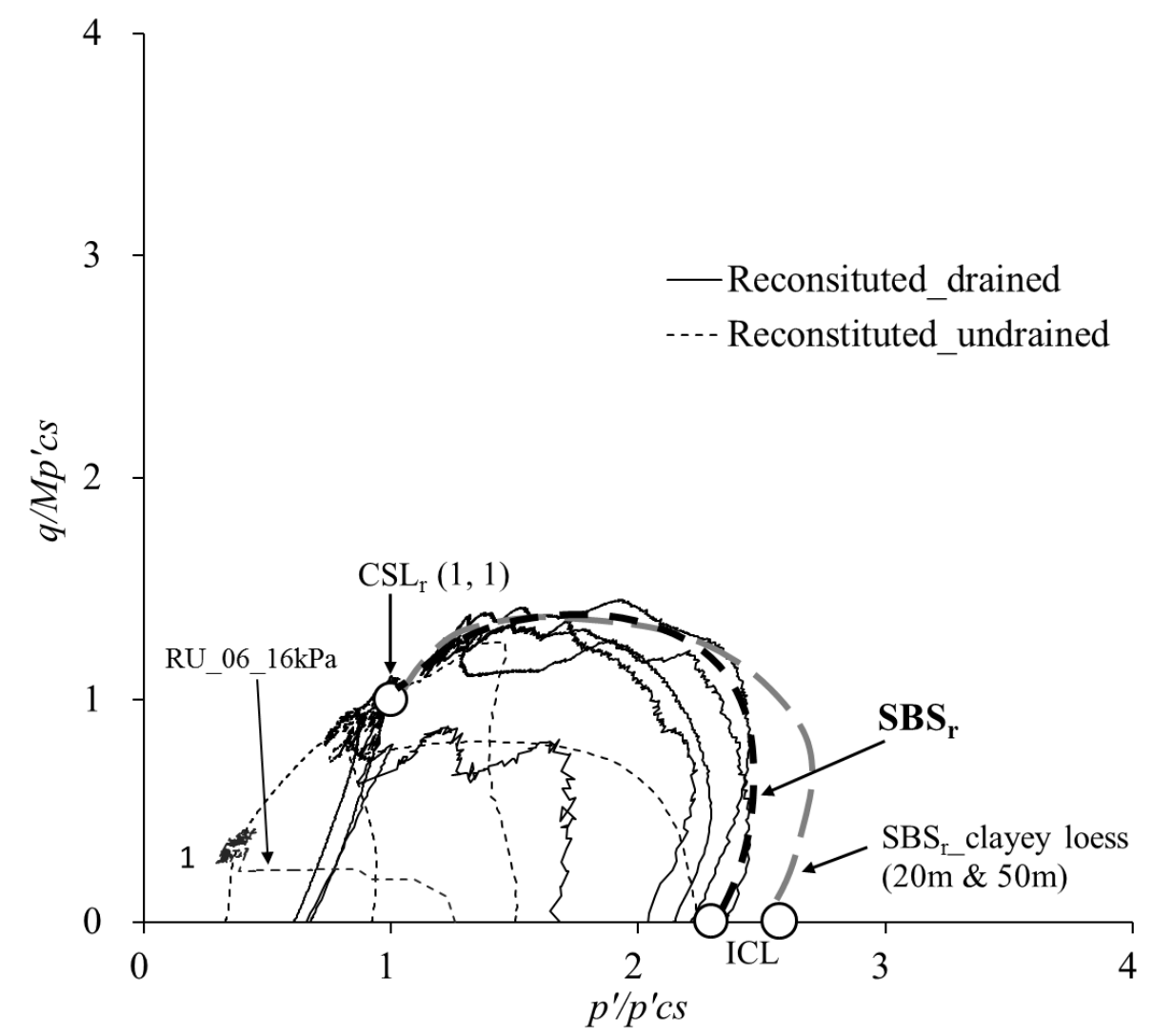

(a)

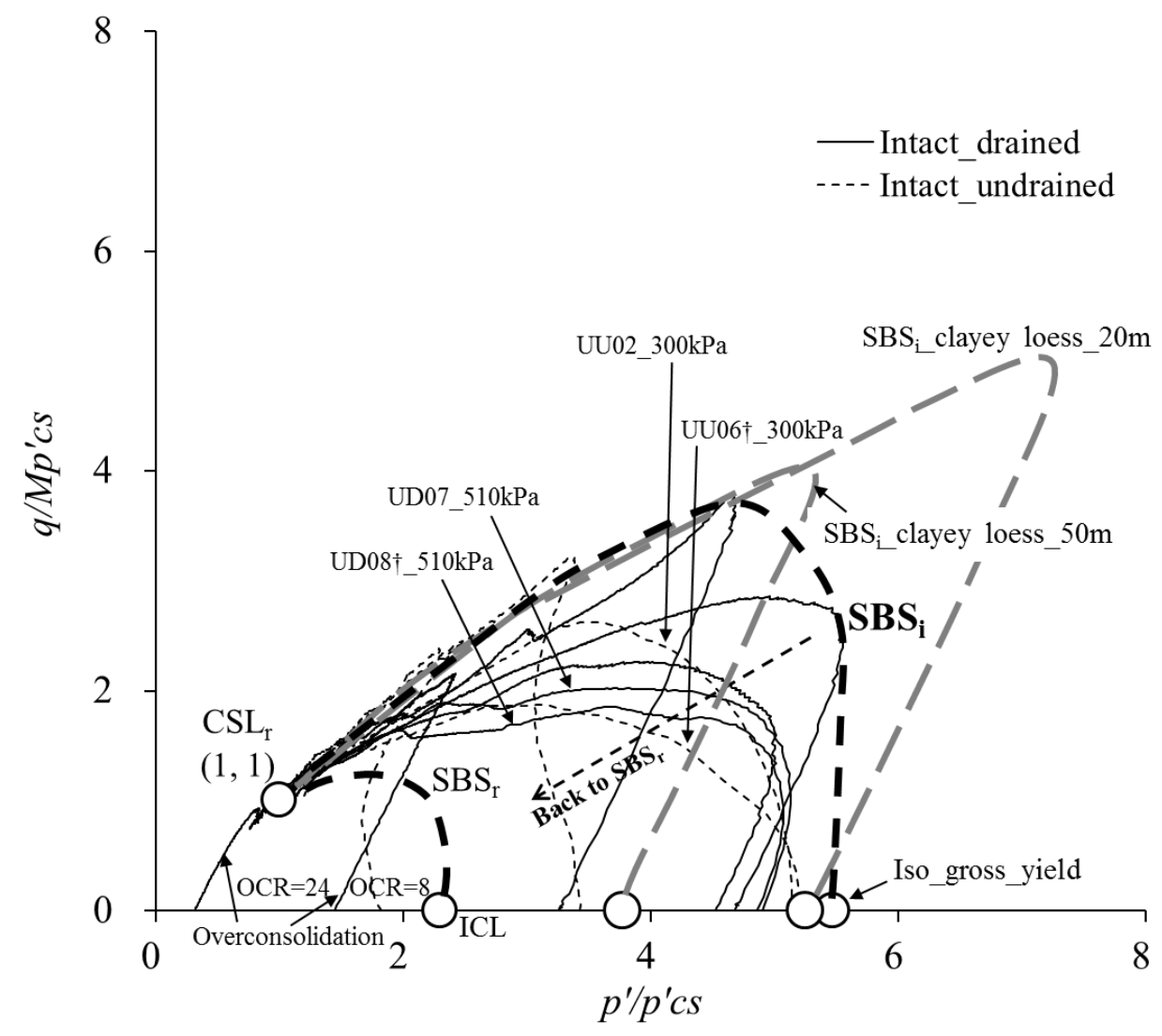

(b) 


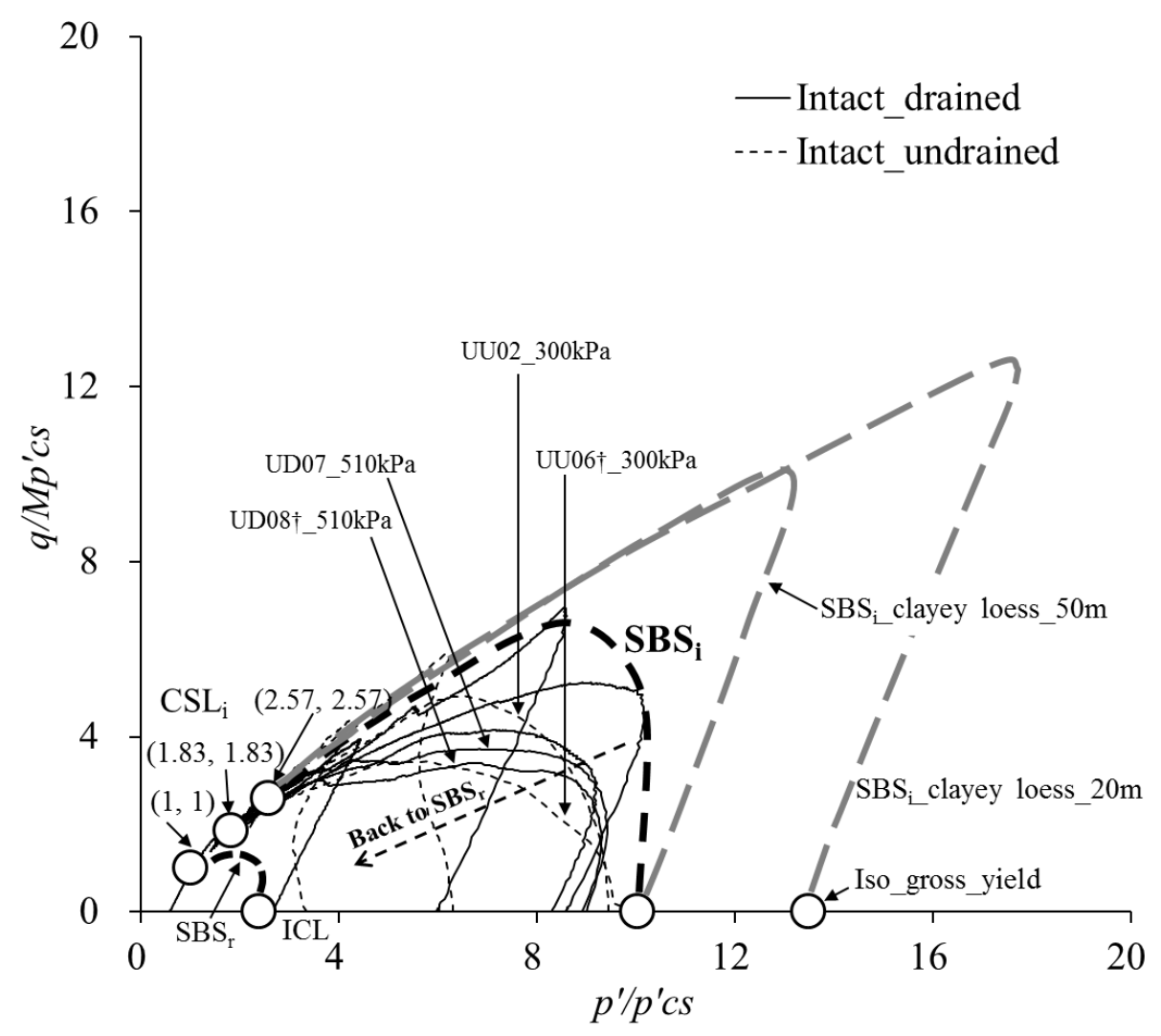

(c)

Fig.15. Normalized stress-paths of intact and reconstituted loess (a) Stress-paths of reconstituted samples normalized by $p_{c s}^{\prime}$ using the intrinsic $C S L$; (b) Stress-paths of intact samples normalized by $p_{c s}^{\prime}$ using intact $C S L$; (c) Stress-paths of intact samples normalized by $p_{c s}^{\prime}$ using intrinsic $C S L$

Note: †Horizontal sample 